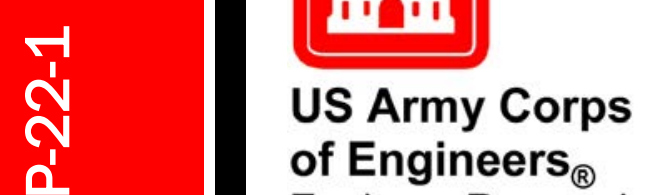

Engineer Research and

Development Center

\title{
Sampling Interplanetary Dust from Antarctic Air
}

S. Taylor, J. H. Lever, K. D. Burgess, R. M. Stroud,

January 2022

D. E. Brownlee, L. R. Nittler, A. Bardyn, C. M. O'D. Alexander,

K. A. Farley, J. Treffkorn, S. Messenger, and

P. J. Wozniakiewicz 
The U.S. Army Engineer Research and Development Center (ERDC) solves the nation's toughest engineering and environmental challenges. ERDC develops innovative solutions in civil and military engineering, geospatial sciences, water resources, and environmental sciences for the Army, the Department of Defense, civilian agencies, and our nation's public good. Find out more at www.erdc.usace.army.mil.

To search for other technical reports published by ERDC, visit the ERDC online library at https://erdclibrary.on.worldcat.org/discovery. 


\section{Sampling Interplanetary Dust from Antarctic Air}

S. Taylor and J.H. Lever

U.S. Army ERDC Cold Regions Research and Engineering Laboratory, Hanover, NH 03775

K.D. Burgess and R.M. Stroud

Materials Science and Technology Division, Naval Research Laboratory, Washington, DC 20375

D.E. Brownlee

Department of Astronomy, University of Washington, Seattle, WA 91195

L.R. Nittler, A. Bardyn, and C.M. O’D. Alexander

Earth and Planets Laboratory, Carnegie Institute for Science, Washington, DC 20015

K.A. Farley and J. Treffkorn

Caltech, Pasadena, CA 91125

S. Messenger

NASA Johnson Space Center, ARES, Houston, TX 77058

P.J. Wozniakiewicz

School of Physical Sciences, University of Kent, Canterbury, CT2 7NH, UK

Final report

Approved for public release; distribution is unlimited.

Prepared for National Aeronautics and Space Administration Houston, TX 77058

Under NASA Emerging Worlds Program and NSF Antarctic Program 


\section{Preface}

This study was conducted for the National Aeronautics and Space Administration (NASA) under funding provided by NASA's Emerging Worlds Program. Dr. Jeff Grossman was the program manager. Added support was provided by the National Science Foundation (NSF) Antarctic Program. Dr. Scott Borg was the program manager.

The work was performed by the NASA Johnson Space Center, Naval Research Laboratory, University of Washington, Carnegie Institute for Science, Caltech, University of Kent, and the U.S. Army Engineer Research and Development Center, Cold Regions Research Engineering Laboratory (ERDC-CRREL). At the time of publication of this paper, the deputy director for ERDC-CRREL was Mr. Bryan E. Baker and the director was Dr. Joseph Corriveau.

This article was originally published online in Meteoritics \& Planetary Science on 27 May 2020.

COL Teresa A. Schlosser was the Commander of ERDC and the director was Dr. David W. Pittman.

DISCLAIMER: The contents of this report are not to be used for advertising, publication, or promotional purposes. Citation of trade names does not constitute an official endorsement or approval of the use of such commercial products. All product names and trademarks cited are the property of their respective owners. The findings of this report are not to be construed as an official Department of the Army position unless so designated by other authorized documents. 


\title{
Sampling Interplanetary Dust from Antarctic Air
}

\begin{abstract}
We built a collector to filter interplanetary dust particles (IDPs) larger than $5 \mu \mathrm{m}$ from the clean air at the Amundsen Scott South Pole station. Our sampling strategy used long duration, continuous dry filtering of near-surface air in place of short duration, high-speed impact collection on flags flown in the stratosphere. We filtered $10^{7} \mathrm{~m}^{3}$ of clean Antarctic air through $20 \mathrm{~cm}$ diameter, $3 \mu \mathrm{m}$ filters coupled to a suction blower of modest power consumption (5-6 kW). Our collector ran continuously for 2 years and yielded 41 filters for analyses. Based on stratospheric concentrations, we predicted that each month's collection would provide 300-900 IDPs for analysis. We identified 19 extraterrestrial (ET) particles on the $66 \mathrm{~cm}^{2}$ of filter examined, which represented $\sim 0.5 \%$ of the exposed filter surfaces. The 11 ET particles larger than $5 \mu \mathrm{m}$ yield about a fifth of the expected flux based on $>5 \mu \mathrm{m}$ stratospheric ET particle flux. Of the 19 ET particles identified, four were chondritic porous IDPs, seven were FeNiS beads, two were FeNi grains, and six were chondritic material with FeNiS components. Most were $<10 \mu \mathrm{m}$ in diameter and none were cluster particles. Additionally, a carbon-rich candidate particle was found to have a small ${ }^{15} \mathrm{~N}$ isotopic enrichment, supporting an ET origin. Many other candidate grains, including chondritic glasses and $\mathrm{C}$-rich particles with $\mathrm{Mg}$ and $\mathrm{Si}$ and $\mathrm{FeS}$ grains, require further analysis to determine if they are ET. The vast majority of exposed filter surfaces remain to be examined.
\end{abstract}

\section{INTRODUCTION}

Extraterrestrial (ET) materials that are collected on Earth include interplanetary dust particles (IDPs) collected in the stratosphere and micrometeorites (MMs) collected at the Earth's surface (Taylor et al. 2016a). Among them, the chondritic porous anhydrous particles (CP-IDPs) are thought to originate from comets (Ishii et al. 2008). They are characterized by the presence of anhydrous crystalline phases, amorphous phases such as GEMS (glass with embedded metal and sulfides; Bradley 1994); high abundances of presolar grains (Messenger et al. 2003; Busemann et al. 2009); high organic C contents (Thomas et al. 1993); and H, $\mathrm{C}$, and/or $\mathrm{N}$ isotopic anomalies in the organics (Messenger 2000). Interestingly, both CP-IDPs and larger ultra-carbonaceous micrometeorites (UCAMMs), 
likely also of cometary origin, were recently collected by melting large volumes of Antarctic snow (Dobrica et al. 2009; Duprat et al. 2010; Dartois et al. 2013; Noguchi et al. 2015). The presence of highly primitive ET materials in recent Antarctic snow indicates that they may also be collected directly from the air, thus allowing laboratory analysis of potentially cometary particles with minimal terrestrial alteration.

Since the 1970s, IDPs have been collected in the stratosphere with high flying aircraft. Brownlee et al. (1977) examined silicone oil-coated "flags" $\left(20 \mathrm{~cm}^{2}\right)$ exposed in the stratosphere during $200 \mathrm{~h}$ of U2 flights ( $20 \mathrm{~km}$ altitude). They found 300 IDPs in the size range $8-60 \mu \mathrm{m}$ from a swept volume of $2.5 \times 10^{5} \mathrm{~m}^{3}$. This yields a particle concentration of $1.2 \times 10^{-3} \mathrm{~m}^{-3}$ assuming $100 \%$ collection efficiency. Zolensky and Mackinnon (1985) analyzed particles larger than $1 \mu \mathrm{m}$ from a similar collector plate and estimated an IDP concentration of $5 \times 10^{-2} \mathrm{~m}^{3}$ for $1-40 \mu \mathrm{m}$ sized particles, with $5 \%$ or $2.5 \times 10^{-3} \mathrm{~m}^{-3}$ being larger than $5 \mu \mathrm{m}$. To avoid using flags coated with silicone oil, Messenger et al. (2015) collected IDPs in the stratosphere using polyurethane foam bonded to a $30 \mathrm{~cm}^{2}$ flag. They collected 14 particles larger than $2 \mu \mathrm{m}$ during $8 \mathrm{~h}$ of flight, or $8.1 \times 10^{-4} \mathrm{~m}^{-3}$. This lower concentration probably reflected the difficulty of finding the IDPs within the foam compared with the silicone oil-coated flags.

Direct filtering of air has advantages over stratospheric capture or terrestrial melting and filtering of snow and ice. These include low stress on the particles, no contamination by oil and solvents, minimizing contact with liquid water, a continuous record of IDP fluxes and characteristics, and lower costs. Air filtering was first tried at the South Pole with an electrostatic precipitation particle collector (Witkowski 1988). That experiment ran for over 2 years, and although many particles were collected only one had chondritic elemental ratios. Identifiable contaminants included sulfuric acid droplets and sooty carbonaceous material. Wozniakiewicz et al. (2014) filtered air from the island of Kwajalein in the Republic of the Marshall Islands by means of a commercial air sampler that pulled $8 \times 10^{-3} \mathrm{~m}^{3} \mathrm{~s}^{-1}$ of air up through a rain hood and down through a $20 \times 25 \mathrm{~cm}, 5 \mu \mathrm{m}$ polycarbonate filter. The filters were washed to remove salt encrustations and concentrate particles, some of which had morphologies or compositions consistent with MM. Similar equipment is being used to sample air atop Mauna Loa, Hawaii (Ishii et al. 2017) and at the Halley research station in Antarctica (Alesbrook et al. 2017).

The South Pole has many advantages for this type of collection. Lack of upwind human activity, depression of the tropopause, general lack of deep atmospheric convection, and high altitude $(2835 \mathrm{~m})$ greatly reduces the flux of terrestrial contaminants in the air. NOAA operates the Atmospheric Research Observatory (ARO) at South Pole as a clean air reference station. The air is extremely clean and has the fewest measured aerosols on Earth (Hogan et al. 1979). The austral summer aerosols are primarily sulfuric acid droplets, $0.03-0.005 \mu \mathrm{m}$ in diameter (Ito 1985) whose numbers $\left(\sim 300\right.$ per $\left.\mathrm{cm}^{3}\right)$ decrease by an order of magnitude during the austral winter relative to their summer peak (Bodhaine and Murphy 1980). During the austral winter, sea salt and ammonium sulfate particles are the primary aerosol (Ito 1985) that arrive at the Pole when storms off the Antarctic coast advect ocean air into the continent. Less than $2 \%$ of the aerosols derive from the terrestrial crust (Hogan et al. 1979). The main disadvantage of sampling at South Pole is its relative inaccessibility. Any shipping, constructing, testing, or modifying associated with the collector has to occur during the 4-month summer season. Additionally, samples are also returned during this 4month window providing little time for the analyses needed to refine collecting procedures before the station closes for the winter.

We built and operated a collector, with an order of magnitude higher flow rate than commercial samplers, to filter IDPs larger than $5 \mu \mathrm{m}$ from ultra-clean air at the Amundsen Scott South Pole station (Taylor et al. 2016b). Based on stratospheric concentrations, we estimated that each month's collection would provide 300-900 IDPs for analysis. Such a large, clean, and time-stamped collection would make it possible to (1) characterize the meteoroid complex throughout the year; (2) identify episodic or periodic events such as meteor streams (Messenger, 2002); (3) collect rare, large $(>30 \mu \mathrm{m})$ cluster particles. Cluster particles are important as they preserve the mineral associations of hundreds of constituent grains providing insight into the conditions of their formation. Also, their short atmospheric residence times ( $<1$ day) allow them to be associated with specific events such as fireballs or meteor-stream crossings.

Here, we describe our experimental design and the results obtained on ET particles from 15 filters examined. Additionally, we report on the ${ }^{3} \mathrm{He}$ measurements made on 13 of the 41 filters collected during the 2-year test. Helium-3 is a stable nonradiogenic isotope that is in quite high concentration in IDPs but not in terrestrial samples. The high concentrations arise from the implantation of solar wind ions on or near IDP surfaces while the IDPs are in space. As solar wind ${ }^{3} \mathrm{He} /{ }^{4} \mathrm{He}$ ratios are far higher than terrestrial ones, ${ }^{3} \mathrm{He}$ can be used as an ET tracer. 


\section{MATERIALS AND METHODS}

\section{The Collector}

In 2016, we designed, built, tested, and installed a collector to suction IDPs from the clean air sector at South Pole station. Important design considerations were that it be simple, suction air at approximately the average wind speed at South Pole $\left(5-6 \mathrm{~m} \mathrm{~s}^{-1}\right)$ to minimize disrupting the air stream, work at cold temperatures, and allow for easy filter exchanges while keeping the filters clean. We anticipated monthly manual filter changes, with the option of more frequent changes if desired.

Winds at the South Pole entrain essentially all IDPs of interest. IDPs have decelerated to their settling velocities by the time they reach stratospheric altitudes, and they slow about 10\% more at near-surface air viscosities. Assuming Stokes flow, IDP settling velocities for spherical particles range from about $10^{-3} \mathrm{~m} \mathrm{~s}^{-1}$ for a $5 \mu \mathrm{m}$ particle of density $1 \mathrm{~g} \mathrm{~cm}^{-3}$ to $0.3 \mathrm{~m} \mathrm{~s}^{-1}$ for a $50 \mu \mathrm{m}$ particle of density $3 \mathrm{~g} \mathrm{~cm}^{-3}$ (Flynn and Sutton 1991). Irregularly shaped IDPs should settle more slowly. Consequently, we oriented our collector pipe horizontally to ingest the wind-entrained IDPs. Somewhat arbitrarily we selected a target of 300 IDPs larger than $5 \mu \mathrm{m}$ to be collected for each monthly filter exposure. At an intake speed of $5 \mathrm{~m} \mathrm{~s}^{-1}$ through a $3 \mu \mathrm{m}$ filter, this target set the filter diameter at $20 \mathrm{~cm}$ and the suction blower power requirement at $5 \mathrm{~kW}$. We thus expected to collect about one IDP per $\mathrm{cm}^{2}$ of filter area per month of exposure, equivalent to $50-200 \mathrm{~h}$ of stratospheric flights.

The collector was in a dedicated building placed on a raised snow berm located on the border of the clean air sector (Fig. 1A). The air intake pipe was $8 \mathrm{~m}$ above the snow surface to minimize ingesting blowing snow that travels near the snow surface (Mellor 1965). Air was drawn in through a $20 \mathrm{~cm}$ diameter aluminum pipe and then a $20 \mathrm{~cm}$ diameter filter unit (Fig. 1B). The filter unit consisted of a polycarbonate membrane $(3 \mu \mathrm{m}$ pores at a density of $2 \times 10^{6}$ pores per $\mathrm{cm}^{2}$ ) clamped between two aluminum rings held together with cable ties (Fig. 1C). The filter units were assembled in a clean room and then shipped to South Pole where they were sequentially inserted and clamped in the collector (Fig. 1D). We selected aluminum for the collector components (6061 T-6) as aluminum is easy to recognize as a contaminant compared to stainless steel or mixed metals, and it is more durable than most plastics at the low temperatures and high wind speeds possible at South Pole. Power was obtained via a buried electrical cable from the ARO. Our NSF assigned research associate made weekly measurements on the blower current draw, flow rate, pressure drop across the filter, and the temperatures entering and exiting the collector (Appendix S1 in supporting information). Most importantly, the associate changed the filters during the year, nominally at monthly intervals.

Daily weather summaries showed generally steady winds $\sim 5 \mathrm{~m} \mathrm{~s}^{-1}$, from the northeast quadrant (clean sector). During the 2 years of the project, winds were from the clean air sector $92 \%$ of the time, intermediate to published values, $89 \%$ (Sheridan et al. 2016) and $98 \%$ (Bodhaine et al. 1986). NOAA noted clean air sector violations (Appendix S1), generally local, shortterm occurrences (e.g., snowmobile deliveries to ARO) that could nevertheless impact our samples. We had hoped to develop a "wind-vane" mechanism to ensure that the intake always pointed directly into the wind, but dropped this option owing to time constraints.

\section{Sample Preparation and ET Searching Techniques}

Our group used a variety of approaches to search for ET particles. Using a light microscope, we searched small areas of filters SPA-4, 5, 12 for rare, $>30 \mu \mathrm{m}$ cluster particles. A total of 70 particles were manually removed and examined with an SEM. We also used SEMs to examine sections of filters (SPA-3, 4, 10, 11, 14, 17, and 22) mounted on Al stubs or on microscope slides. The filter pieces were cut using stainless steel scissors and attached to double-sided $\mathrm{C}$ or $\mathrm{Cu}$ tape before coating with $\mathrm{C},<30 \mathrm{~nm}$ thickness, or Ir (SPA-4 and 11). Magnesium and Fe element maps were made of the Ir-coated samples $(200 \mu \mathrm{m} \times 300 \mu \mathrm{m}$ frames $)$ to identify candidate ET particles. Lastly, we removed particles from $\mathrm{cm}^{2}$ filter sections by pressing a C sticky mat against the filter (SPA-1, 4, 10, 17, 35, 39). Generally, the C mat was pressed once onto the filter but in the case of SPA-5, we also made a $0.5 \mathrm{~cm}^{2}$ "stamp" used to lift particles from a $\sim 4 \mathrm{~cm}^{2}$ section of the filter.

We looked for high Z (bright) grains, fluffy (multiple components) particles, spheres, and low Z (dark) grains composed mainly of $\mathrm{C}$. High $\mathrm{Z}$ particles often contained $\mathrm{Ni}$. In the absence of $\mathrm{Cr}$ or $\mathrm{Ti}, \mathrm{Ni}$ in $\mathrm{Fe}$ or sulfides is rare in terrestrial materials and is considered ET. Multiple components particles with intricate structure are characteristics of IDPs not shared by most contaminants. Spheres indicate complete melting, which can occur as ET grains are heated in Earth's atmosphere. Lastly, as C-rich particles often result from combustion, we focused on those $\mathrm{C}$ grains containing $\mathrm{N}$, a signature of $\mathrm{ET}$ organic matter, or $\mathrm{Ni}$ or both.

Particles were determined to be ET if their appearance, internal texture, and elemental composition 

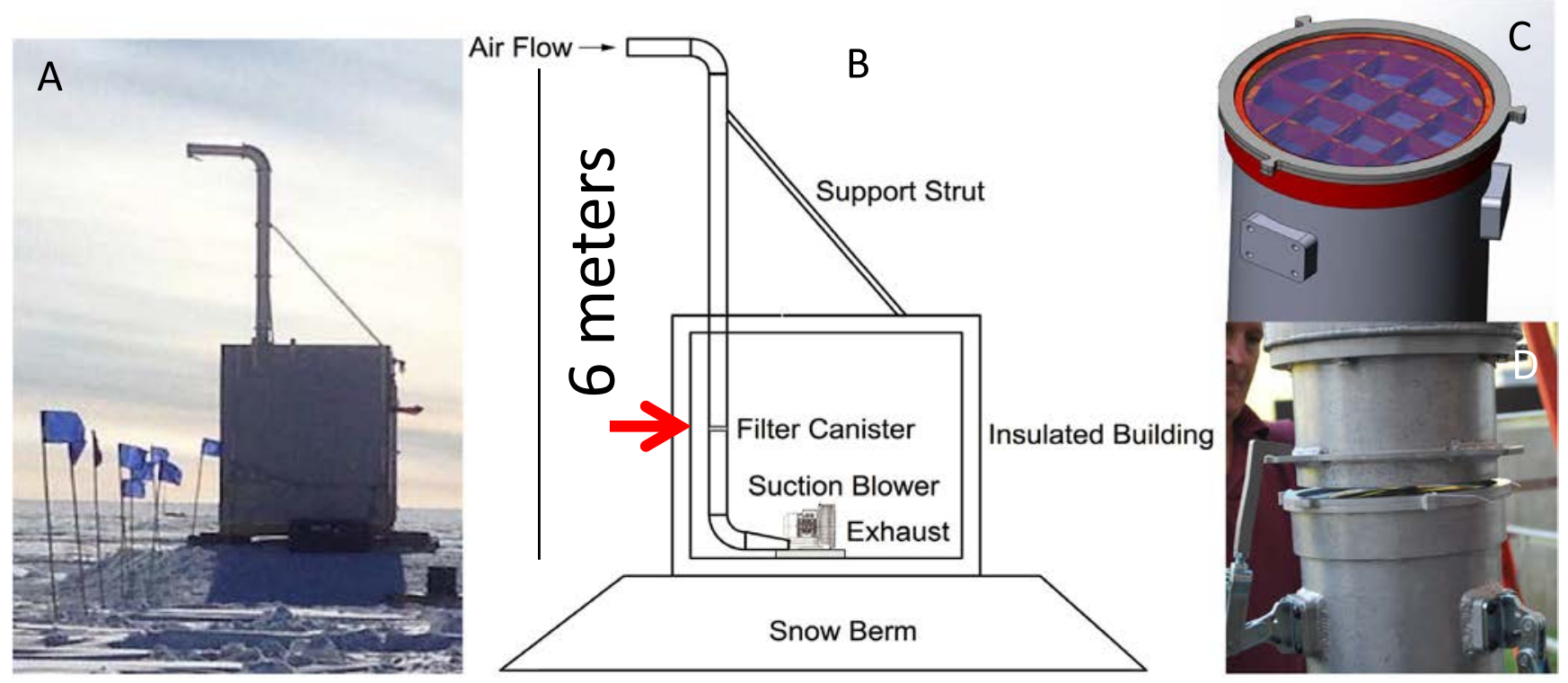

Fig. 1. A) Photo of building housing our experiment at South Pole. B) Schematic of the collector, arrow shows the location of the filter unit in the intake pipe. C) Schematic of filter unit. D) Image of filter unit in the pipe and toggles used to secure it. (Color figure can be viewed at wileyonlinelibrary.com.)

were consistent with the criteria used by NASA to designate particles as "cosmic" (Cosmic Dust Catalogs). Texturally, these include irregular to round shapes and particles composed of aggregate grains and porous textures. Compositionally these include the presence of $\mathrm{FeNi}$ or $\mathrm{FeNiS}$, particles containing $\mathrm{Mg}, \mathrm{Si}, \mathrm{Fe}$ in various ratios with small amounts of $\mathrm{S}$ or $\mathrm{Ni}$ or both.

We labelled as possible or "candidate" ET particles those containing Mg-rich anhydrous minerals such as olivines and pyroxenes; glass grains that contained $\mathrm{Mg}$, $\mathrm{Si}, \mathrm{Ca}, \mathrm{Fe}$ but no $\mathrm{Ni}$; and all $\mathrm{N}$ or $\mathrm{Ni}$ containing $\mathrm{C}$ grains. The latter require isotopic analyses to demonstrate that they are ET.

We imaged all the ET particles and also imaged representative types of candidate particles and of common contaminants found on each filter. The filters were stored in the bags and Al holders in which they were received, and every effort was made to avoid contamination in the lab. Filters are now curated at Johnson Space Center in Houston, and will be available for request from the Astromaterials Research and Exploration Science division.

\section{Electron Beam Analytical Methods}

\section{Scanning Electron Microscopy}

S.T. (with students Amanda Pinson and Summer Christenson) used an FEI Scios 2 scanning electron microscope (SEM) located at Dartmouth College. The secondary electron detector highlighted topography while the backscatter electron detector highlighted composition (atomic number). An energy-dispersive Xray (EDS) spectrometer provided quantitative compositional data. Imaging and EDS was mostly done at $20 \mathrm{kV}$.

R.S. and K.B. (with student intern David Bour) used an FEI Helios G3 FIB-SEM and FEI Nova 600 FIB-SEM at the Naval Research Laboratory to search for particles. A secondary electron image with FOV 518 or $638 \mu \mathrm{m}$, provided a large search area while seeing particles $>\sim 3 \mu \mathrm{m}$ (size of filter holes). Each particle within this FOV was measured using EDS spot analysis for "bulk" composition. Imaging and EDS was mostly done at $15 \mathrm{kV}$ in order to include $\mathrm{Fe}-\mathrm{K} \alpha$, but some measurements were done at $5 \mathrm{kV}$, which shows surface structure of the particles with more detail.

A.B., C.A., and L.N. used a JEOL 6500F SEM at the Carnegie Institution of Washington (CIW). About 1 $\mathrm{cm}^{2}$ of filter was cut, placed on a C sticky tab, and coated with Ir. SEM and EDS maps were acquired at $15 \mathrm{kV}$ with a frame size of $200 \times 300 \mu \mathrm{m}$. Candidate ET grains were identified as hotspots in $\mathrm{Mg}$ and $\mathrm{Fe}$ EDS maps and reanalyzed at high magnification.

\section{TEM Sample Preparation}

K.B. used an FEI Helios G3 at NRL for focused ion beam (FIB) to section three ET grains and a few candidate grains. After deposition of a protective $\mathrm{C}$ strap, samples were milled using a $30 \mathrm{kV} \mathrm{Ga}^{+}$beam, and final thinning for most samples was done at lower voltage, $5 \mathrm{kV}$. K.B. also embedded one particle in $\mathrm{S}$ and used an ultramicrotome equipped with a diamond knife 
to section it for analysis by both NanoSIMS and STEM. Samples for NanoSIMS were cut to a thickness of $150 \mathrm{~nm}$ and mounted on an Si wafer, while samples for STEM were $70 \mathrm{~nm}$ thick and mounted on 200 mesh $\mathrm{Cu}$ TEM grids with a $\mathrm{C}$ support film. The sulfur was removed by sublimation in a $60{ }^{\circ} \mathrm{C}$ oven for at least $2 \mathrm{~h}$.

\section{Scanning Transmission Electron Microscopy}

K.B. used the Nion UltraSTEM200-X at NRL for scanning transmission electron microscopy (STEM) analyses. The microscope is equipped with a Gatan Enfinium ER spectrometer for electron energy loss spectroscopy (EELS) and a windowless, 0.7 sr Bruker SDD detector for energy dispersive spectroscopy (EDS). The STEM was operated at $60 \mathrm{kV}$ for carbon-rich samples and $200 \mathrm{kV}$ for silicate and sulfide samples. Images were collected using bright field and high-angle annular dark field modes.

\section{Nano Secondary Ion Mass Spectroscopy}

L.N. and A.B. used the Cameca nano secondary ion mass spectroscopy (NanoSIMS) 50L ion microprobe at $\mathrm{CIW}$ to measure $\mathrm{Mg}$ - $\mathrm{Al}$ isotopes in one $\mathrm{ET}$ particle (SPA-1) mounted on $\mathrm{C}$ sticky tape and $\mathrm{H}, \mathrm{C}$, and $\mathrm{N}$ isotopes in microtomed slices of a $\mathrm{C}$-rich candidate $\mathrm{ET}$ particle. For the Mg-Al measurements, an $\sim 100 \mathrm{~nm}$, $\sim 4 \mathrm{pA} \mathrm{O}^{-}$primary beam was rastered $(256 \times 256$ pixels, $8 \mu \mathrm{m})$ over the sample with simultaneous collection of ${ }^{23} \mathrm{Na},{ }^{24,25,26} \mathrm{Mg},{ }^{27} \mathrm{Al},{ }^{28} \mathrm{Si}$, and ${ }^{56} \mathrm{Fe}$ positive secondary ions in multicollection mode. For the $\mathrm{H}, \mathrm{C}$, and $\mathrm{N}$ measurements, a focused $\mathrm{Cs}^{+}$primary ion beam was used, again in multicollection imaging mode $(256 \times 256$ pixels, $20-22 \mu \mathrm{m})$. An $\sim 4 \mathrm{pA}$ beam was used for the $\mathrm{H}$ measurements, with collection of ${ }^{1} \mathrm{H}^{-},{ }^{2} \mathrm{H}^{-},{ }^{12} \mathrm{CH}^{-}$, and ${ }^{18} \mathrm{O}^{-}$ions, whereas for $\mathrm{C}$ and $\mathrm{N}$, an $\sim 1 \mathrm{pA}$ beam was used and ${ }^{12} \mathrm{C}_{2}^{-},{ }^{12} \mathrm{C}^{13} \mathrm{C}^{-},{ }^{12} \mathrm{C}^{14} \mathrm{~N}^{-},{ }^{12} \mathrm{C}^{15} \mathrm{~N}^{-}$, and ${ }^{28} \mathrm{Si}^{-}$ secondary ions were measured. Images were analyzed with the L'image software (L. Nittler, CIW) following essentially the same methods described by Nittler et al. (2018). A synthetic organic powder with known isotopic composition was used as an isotope standard for the $\mathrm{H}$ measurements. For $\mathrm{C}$ and $\mathrm{N}$, insoluble organic matter extracted from a CR chondrite meteorite and microtomed slices of superglue were used as standards.

\section{Helium-3 Measurements}

K.F. and J.T. made ${ }^{3} \mathrm{He}$ measurements on 180 , $1 \mathrm{~cm}^{2}$ subsamples cut from 13 of the polycarbonate filters to determine if they contained ET material, to look for a seasonal variation in the ET flux and to check if the airflow was even across the filter. They also measured ${ }^{3} \mathrm{He}$ on 10 Whatman glass filters $(47 \mathrm{~mm}$ in diameter) used to wipe the insides of the intake pipes at the end of the experiment to check for adhering ET material. Each filter sample, either the $1 \mathrm{~cm}^{2}$ polycarbonate filter subsamples or the glass filters, was placed in a tin foil cup and compressed to form a compact ball. These samples were sent to Caltech and measured with a Thermo Helix SFT mass spectrometer following the procedures used for ${ }^{3} \mathrm{He}$ extraction from seafloor sediments (Patterson and Farley 1998). Unique to these analyses was a decontamination step to protect the vacuum purification line from organic contamination after the polycarbonate filters were analyzed (Farley, personal communication).

\section{RESULTS}

\section{General}

The collector ran well and continuously (except for short weather shut downs) from installation on November 29, 2016 to project end on January 6, 2019. The equipment survived $-75^{\circ} \mathrm{C}$ temperatures and $50 \mathrm{~km} \mathrm{~h}^{-1}$ winds. During the 2-year project, forty-one filters were exposed to the air stream for times ranging between 0.25 and 39 days (Fig. 2A). We exposed filters for different lengths of time to assess how aerosol loads affected ET numbers.

We measured the air flow through the filters at $6.6 \pm 1 \mathrm{~m} \mathrm{~s}^{-1}$ and, depending on the exposure time of each filter, the air volume sampled ranged between $4000 \mathrm{~m}^{3}$ and $820,000 \mathrm{~m}^{3}$ (Appendix $\mathrm{S} 1$ ). The pressure drop measured across each filter showed that the filters did not plug significantly (Fig. 2B). The average pressure drop for a clean filter was $15.36 \pm 1.1 \mathrm{kPa}$ (Fig. 2B round markers), whereas it was $18.46 \pm 1.8 \mathrm{kPa}$ for an exposed filter (Fig. 2B open square markers). Although the data are noisy, the general trend was for pressure drop to increase with increasing exposure time, as expected if particles or aerosols progressively plugged the filter pores. The average increase in pressure corresponded to about $25 \%$ of the pores being plugged during exposure and a decrease in flow rate of about $12 \%$. The largest pressure drop $23.25 \mathrm{kPa}$ (3.37 psi) was measured before changing out filter SPA-35. Given the large volume of snow that accumulated on this filter (Fig. 2C), the pressure drop was surprisingly low and corresponded to a decrease in flow rate of only $22 \%$ compared with the average clean-filter value. Clearly, the snow that accumulated on the filters presented less flow restriction than the $3 \mu \mathrm{m}$ filters themselves. If snow was present on the filters, they were carefully removed from the collector to retain the snow and allow it to sublimate or melt in place. 

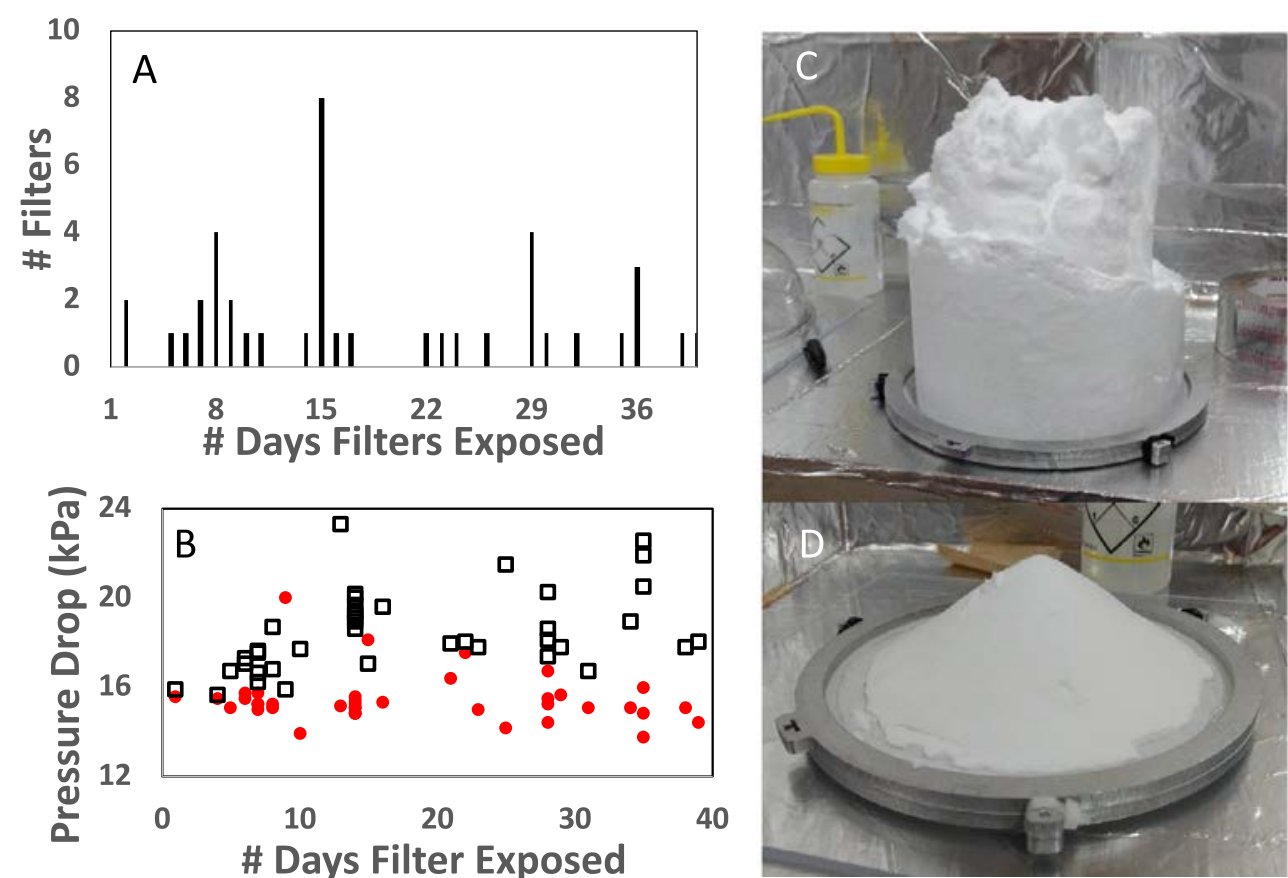

Fig. 2. A) Histogram of number of filters exposed for different number of days. B) Pressure drop across the filter (kPa) as a function of exposure time, $(n=38)$ clean filters shown by round markers, exposed filters shown as open square markers. C) extreme, SPA-35, and D) normal, SPA-31, example of snow deposition on filters during storms. (Color figure can be viewed at wileyonlinelibrary.com.)

Most of the filters appeared optically clean (Fig. 3A), but four were stained, three had a small hole or a rip (Fig. 3B), seven had dark particles on their surfaces, and one was covered with carbon particles (Fig. 3C). The latter, SPA-39, was not different from the other filters in terms of clean air violations or wind from non-clean air sectors (Appendix S1). Even when optically clean, magnification revealed that $\sim 10 \mu \mathrm{m} \mathrm{Al}$ metal from the intake pipe was a significant source of contamination on the filters. As Al particles from collector fabrication diminished with operating time, filters installed later in the experiment had fewer Al grains. Many of the $\mathrm{Al}$ grains were easily distinguished from ET particles by their appearance (Fig. 4A), but some were dark and irregularly shaped like IDPs (Fig. 4B).

We expected most of the aerosols to follow the air stream through the pores. However, given the $\sim 400,000 \mathrm{~m}^{3}$ of air we suctioned each month, some of the sulfuric acid droplets impinged on the filter surface (Fig. 5A), filled the pores (Fig. 5B), or decorated particle surfaces (Fig. 5C). The winter filters had fewer sulfuric acid droplets but many salt grains, some cubic in shape, some rods (Fig. 5D,E). The salt rods are common and often thin and delicate, suggesting that the collection process is gentle enough to not break them (Fig. 5D). The seasonal variation in aerosols noted here agrees with measurements made by others (e.g., Bodhaine et al. 1986).
Other types of particles found include clay minerals, quartz grains, and the occasional diatom (Fig. 6A). We found no $\mathrm{Al}$ oxide spheres that were once common on stratospheric collection flags and thought to derive from rocket exhaust (Brownlee et al. 1976). The Fe-poor Mgsilicates we did find are likely talc contaminants from the weather balloons released at South Pole (Fig. 6BD). These grains have EDS spectra that qualitatively match enstatite, but in fact also match samples of this talc (Fig. 6C) and TEM analysis confirmed that at least one is indeed talc (e.g., see Fig. 14). Many talc particles are released when the balloons are inflated (Fig. 6D) and presumably when they are flown.

\section{ET Particles}

Table 1 summarizes the ET particle search results. We examined $\sim 66 \mathrm{~cm}^{2}$ of filter from 15 different filters exposed to the Antarctic air over the course of 2 years. The average exposure for those filters containing the 19 ET particles was 32 days. We predicted one ET particle $>5 \mu \mathrm{m}$ per $\mathrm{cm}^{2}$ per month and found 0.2 ET particle per 32 days, or about a fifth of the ET particles expected. Of the $19 \mathrm{ET}$ particles, four were chondritic porous IDPs (CP-IDPs), seven were FeNiS beads, two were $\mathrm{FeNi}$ grains, and six had chondritic compositions with FeNiS components. Most were $<10 \mu \mathrm{m}$ in diameter, with an average diameter of $6 \pm 5 \mu \mathrm{m}$ 


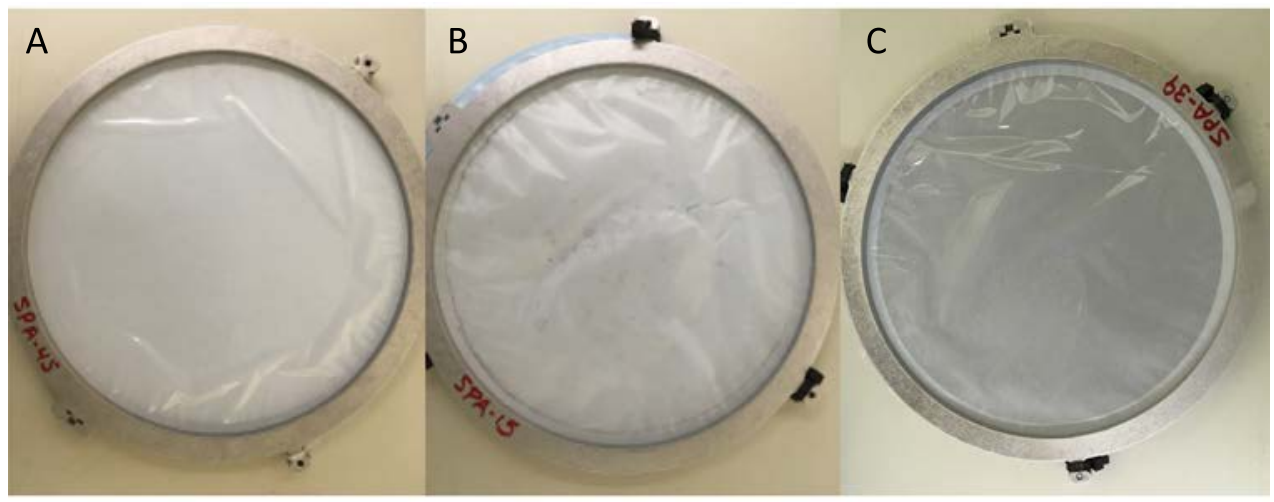

Fig. 3. Example of a clean (A), a dirty and ripped (B), and a singularly dirty (C) filter. The diameter of the filters is $20 \mathrm{~cm}$ resulting in an $\sim 300 \mathrm{~cm}^{2}$ collecting area. (Color figure can be viewed at wileyonlinelibrary.com.)

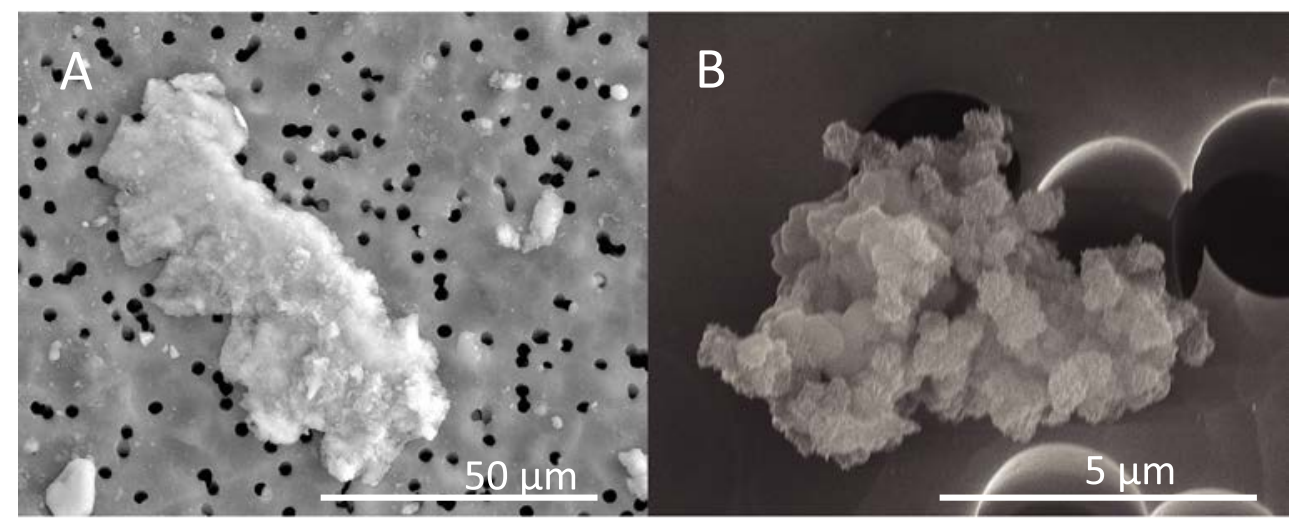

Fig. 4. Secondary electron images of (A) typical Al grains; (B) Al grain that is morphologically similar to a fluffy IDP. (Color figure can be viewed at wileyonlinelibrary.com.)

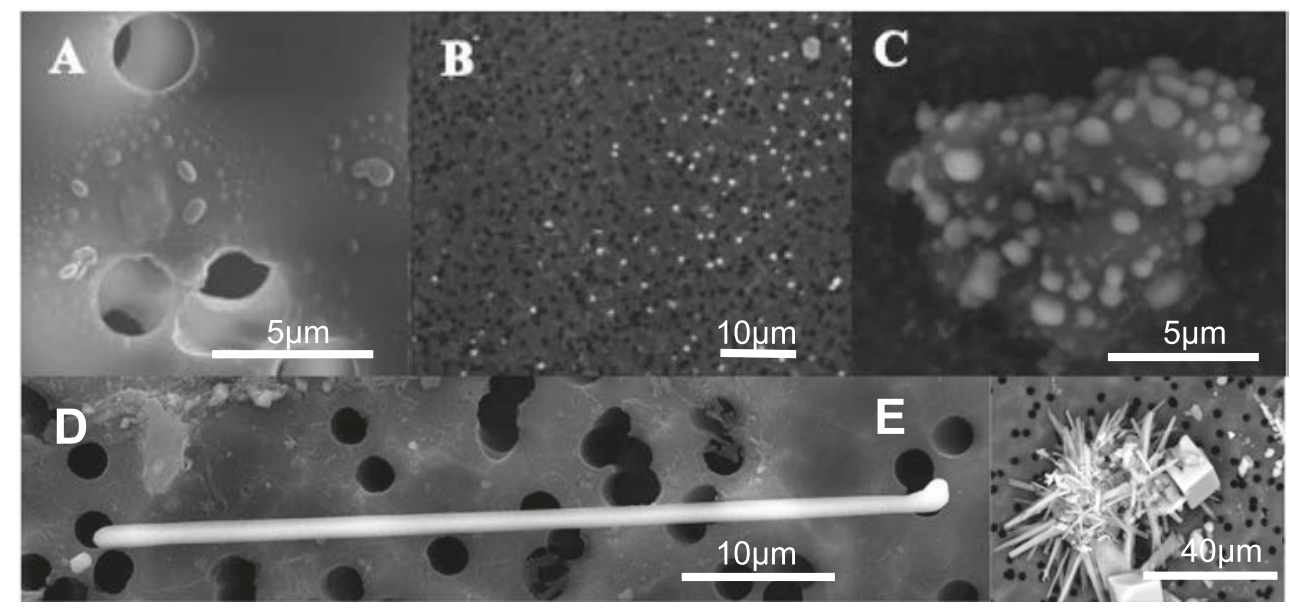

Fig. 5. SEM images of (A) sulfuric acid droplets on a filter, secondary electron; (B) infilled filter pores seen as bright circular features, backscatter electron; (C) sulfuric acid decorating an aluminum grain, backscatter electron; (D) salt rod, backscatter electron; and (E) backscatter electron image of salt crystals and cubes.

$(n=19)$ compared with $11 \pm 6 \mu \mathrm{m}$ measured for stratospheric ET particles $(n=180$; see Cosmic Dust Catalogs, https://curator.jsc.nasa.gov/dust/catalogs/), and none were cluster particles. The appearance of the ET particles collected here was similar to those collected in the stratosphere (Appendix S2 in supporting 

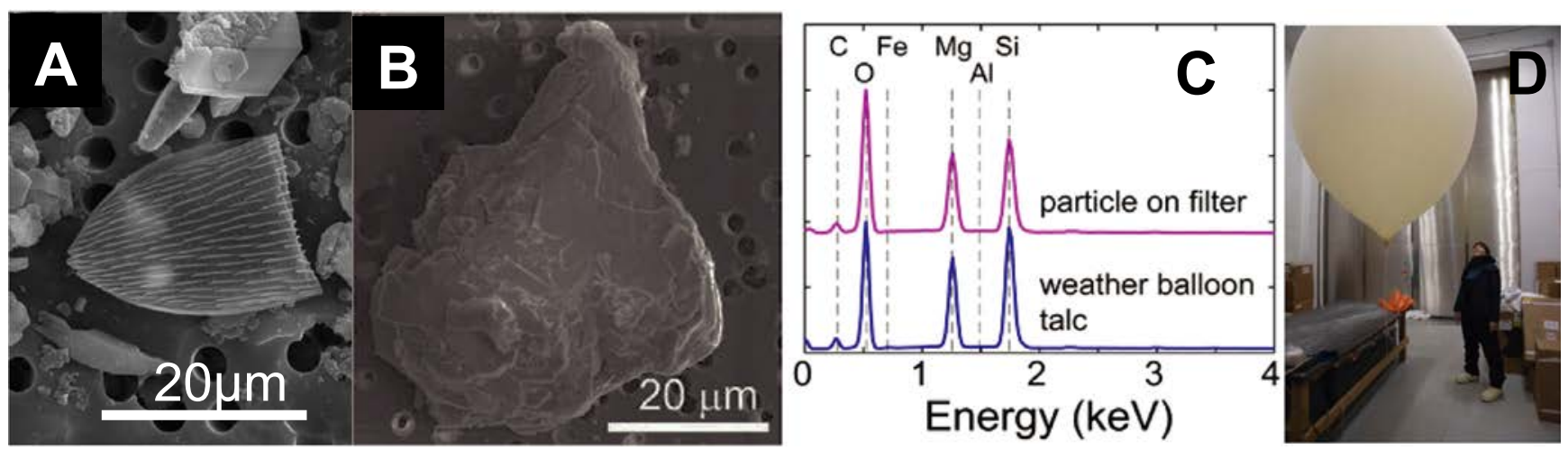

Fig. 6. Secondary electron SEM images of (A) diatom; (B) particle on filter with pyroxene-like EDS spectrum. C) Comparison of a pyroxene-like particle on filter with weather balloon talc; (D) inflation of weather balloon sheds many talc particles that appear as white powder on the table (R. Stroud for scale). (Color figure can be viewed at wileyonlinelibrary.com.)

Table 1. Summary of information obtained from filters examined.

\begin{tabular}{|c|c|c|c|c|c|c|c|c|c|}
\hline Season & Filter \# & $\begin{array}{l}\text { Days } \\
\text { exposed }\end{array}$ & \# ET & $\begin{array}{l}\text { Ave. } \\
\text { diameter } \\
(\mu \mathrm{m})\end{array}$ & $\begin{array}{l}\text { Filter area } \\
\text { examined } \\
\left(\mathrm{cm}^{2}\right)\end{array}$ & $\begin{array}{l}\text { Particles } \\
\text { analyzed }\end{array}$ & $\begin{array}{l}\text { ET particle } \\
\text { composition }\end{array}$ & Method mounted & Examined by \\
\hline \multirow[t]{4}{*}{ Spring 2016} & SPA-1 & 0.25 & 1 & 5 & 1 & & CP-IDP & C sticky & Taylor \\
\hline & SPA-3 & 5 & & 40 & 1 & 238 & UCAMM? & C coated filter & $\begin{array}{r}\text { Stroud \& } \\
\text { Burgess }\end{array}$ \\
\hline & SPA-4 & 35 & 1 & 5 & 2 & 53 & FeNiS bead & Coated filter & $\begin{array}{l}\text { Alexander \& } \\
\text { Bardyn }\end{array}$ \\
\hline & & & 0 & & 2 & & & & Taylor \\
\hline \multirow[t]{5}{*}{ Summer 2017} & SPA-5 & 25 & 2 & $11 \& 15$ & & 50 & FeNiS beads & 50 picked & Brownlee \\
\hline & & & 0 & & & 20 & & 20 picked & Brownlee \\
\hline & & & & & 4 & 15 & Chondritic glass & Stamp & Taylor \\
\hline & SPA-10 & 35 & 2 & $4 \& 9$ & 10.5 & 30 & FeNiS, CP-IDP & $\mathrm{C}$ coated filter $\mathrm{Z}$ & $\begin{array}{l}\text { Pinson \& } \\
\text { Taylor }\end{array}$ \\
\hline & & & 1 & 4 & 10 & 19 & CP-IDP & C coated filter & Taylor \\
\hline \multirow[t]{5}{*}{ Fall 2017} & & & 1 & 9 & 1 & & CP-IDP & C sticky A & Taylor \\
\hline & & & 4 & $1,1,2,3$ & 1 & 7 & $\begin{array}{l}3 \text { beads, } 1 \\
\text { bead }+ \text { chon }\end{array}$ & C sticky B & Taylor \\
\hline & & & 1 & 5 & 1 & 4 & 1 chon + FeNiS & C sticky C & Taylor \\
\hline & & & 1 & 5 & 1 & 3 & 1 chon + FeNiS & C sticky D & Taylor \\
\hline & SPA-12 & 15 & 0 & & 1 & 8 & & & Brownlee \\
\hline \multirow[t]{4}{*}{ Winter 2017} & SPA-14 & 16 & 0 & & 2.5 & 115 & & & $\begin{array}{r}\text { Stroud \& } \\
\text { Burgess }\end{array}$ \\
\hline & SPA-15 & 39 & 0 & & 1 & 5 & & Coated filter & Taylor \\
\hline & SPA-17 & 22 & 0 & & 9.7 & & & C coated filter & Taylor \\
\hline & & & 1 & 10 & 1 & 25 & $\mathrm{FeNi}$ & C sticky A & Taylor \\
\hline \multirow[t]{2}{*}{ Spring 2017} & SPA-21 & 4 & 0 & & 1 & 5 & & Coated filter & Taylor \\
\hline & SPA-22 & 14 & 0 & & 10.8 & 24 & & C coated filter & $\begin{array}{l}\text { Christensen \& } \\
\text { Taylor }\end{array}$ \\
\hline \multirow[t]{2}{*}{ Fall 2018} & SPA-30 & 38 & 4 & $1,4,5,15$ & 1 & 12 & 3 Chon, $1 \mathrm{FeNi}$ & Coated filter & Taylor \\
\hline & SPA-35 & 13 & 0 & & 1 & 10 & & Coated filter & Taylor \\
\hline Spring 2018 & SPA-39 & 7 & 0 & & 1 & 9 & & Coated filter & Taylor \\
\hline Summer 2018 & SPA-45 & 1 & 0 & & 1 & 3 & & Coated filter & Taylor \\
\hline Total & & & 19 & & 65.5 & & & & \\
\hline
\end{tabular}

information). Below, we describe three of the ET particles found. Two are CP-IDPs and one is a melted particle containing FeNiS and silicate minerals.
SPA-1 was the first filter deployed and, although it was exposed for only $5 \mathrm{~h}$, the $1 \mathrm{~cm}^{2}$ section examined contained an IDP (Fig. 7a). The IDP had multiple 


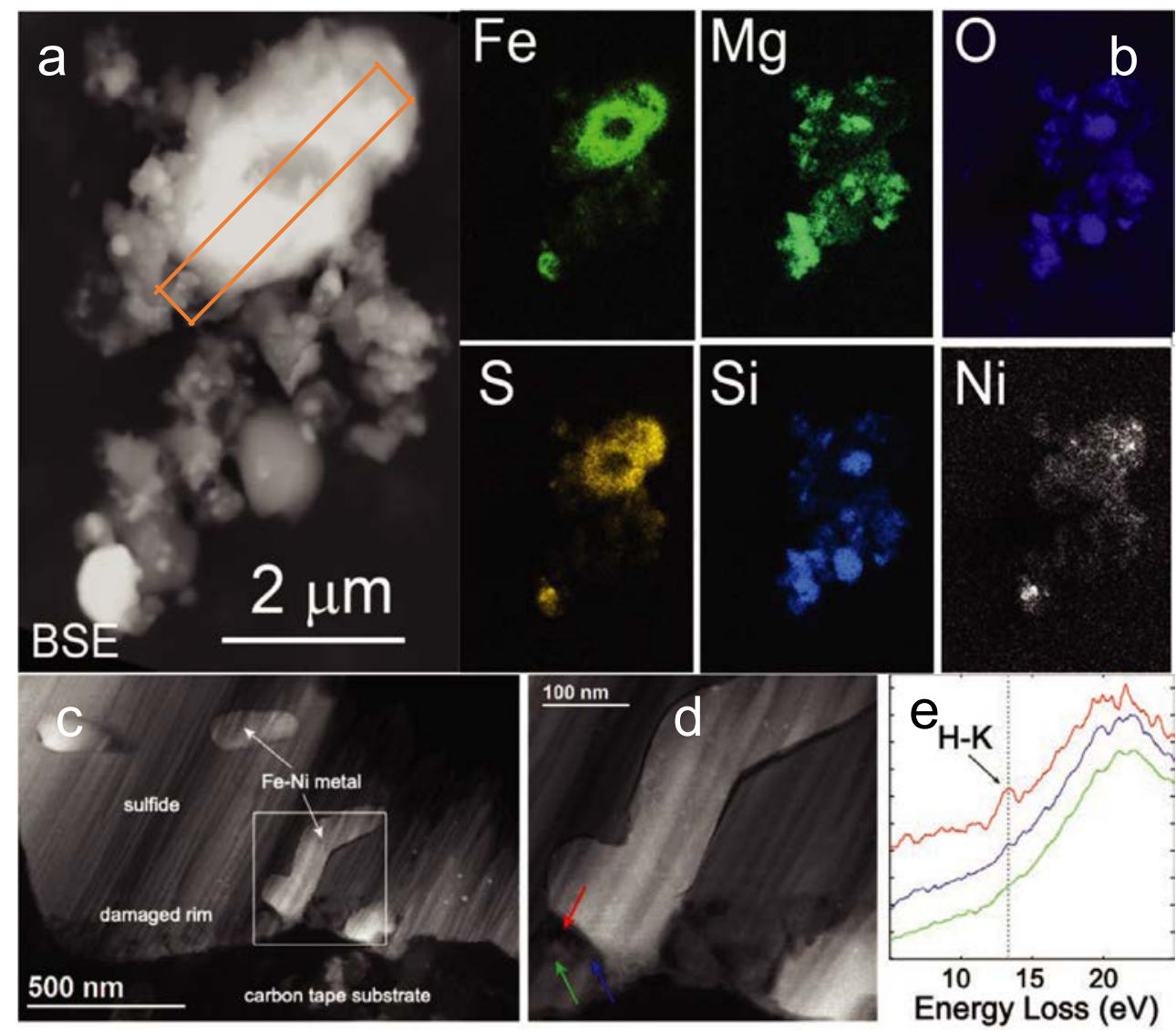

Fig. 7. (A) Backscattered electron (BSE) image of SPA-1 showing location of FIB section; (B) select X-ray maps of IDP; (C) HAADF image of an FIB cross section of sulfide grain with Fe-Ni metal inclusions; (D) close-up of alteration rim; EELS data showing a hydrogen signature in a tiny vesicle. The subvertical lines on the HAADF images are artifacts of FIB preparation.

phases (Fig. 7b, Appendix S2), including an $\sim 2 \mu \mathrm{m} \mathrm{Fe-}$ sulfide, $\mu \mathrm{m}$-sized silicates (olivines and glass); a $1 \mu \mathrm{m}$ FeNiS bead; and an $\sim 500 \mathrm{~nm} \mathrm{Al}$, Na-rich grain (likely a feldspar). We performed Al-Mg analysis of the IDP by NanoSIMS, but the $\mathrm{Mg}$ content of the Al-rich grain was too high to detect extinct ${ }^{26} \mathrm{Al}$.

An FIB section cut through an Fe-sulfide grain and the STEM analysis of the section shows several 100 $400 \mathrm{~nm}$ Fe-Ni metal inclusions (Fig. 7c). The edge of the grain, which was attached to the $\mathrm{C}$ tape substrate and thus protected from ion beam during preparation, shows a damaged rim, likely from exposure to the space environment (Fig. 7d). EELS analyses show a $\mathrm{H}$ signature in the oxidized $\mathrm{Fe}$ and in the vesicles found near the rim, possibly from alteration during atmospheric entry heating (Fig. 7e).

Figure 8 illustrates the variety of ET particles found in $\sim 24 \mathrm{~cm}^{2}$ of filter SPA-10. The particles range from a submicron FeNiS bead (G) to a $15 \mu \mathrm{m}$ CP-IDP (I). Most contained FeNiS and many have fine-grained material composed of $\mathrm{Mg}, \mathrm{Si}$, and $\mathrm{Fe}$ attached (B, C,
D, E, G, I, and J). Below, we describe additional analyses made on particles I and $\mathbf{J}$.

Particle $\mathrm{I}$ is a CP-IDP of chondritic composition (Fig. 8I). The FIB section (Fig. 9A,B) shows crystals of enstatite and a high-Ca pyroxene (Fig. 9C), olivine, Ni pyrrhotite, and magnetite (Fig. 9D, analyses are tabulated in Appendix S3 in supporting information). Magnetite partial rims on some grains indicate atmospheric entry heating. Carbonaceous material is enclosed by one of these magnetite rims. Nickel is present only in the pyrrhotite.

Particle $\mathbf{J}$ is an $\sim 5 \mu \mathrm{m}$ hollow sphere of magnetite, sulfide (Ni pyrrhotite), olivine, and pyroxene, which was likely melted during atmospheric entry (Fig. 10). Minor phases rich in $\mathrm{Ca}$ and in $\mathrm{Al}$ (spinel) are present between the larger grains (phase compositions listed in Appendix S3). EELS confirms that the Fe-oxide phase is magnetite and that the olivine and Fe-sulfide contain no $\mathrm{Fe}^{3+}$. Nickel is present only in the pyrrhotite.

In addition to the bona fide ET particles, we noted several candidate particles that may also be ET. These 

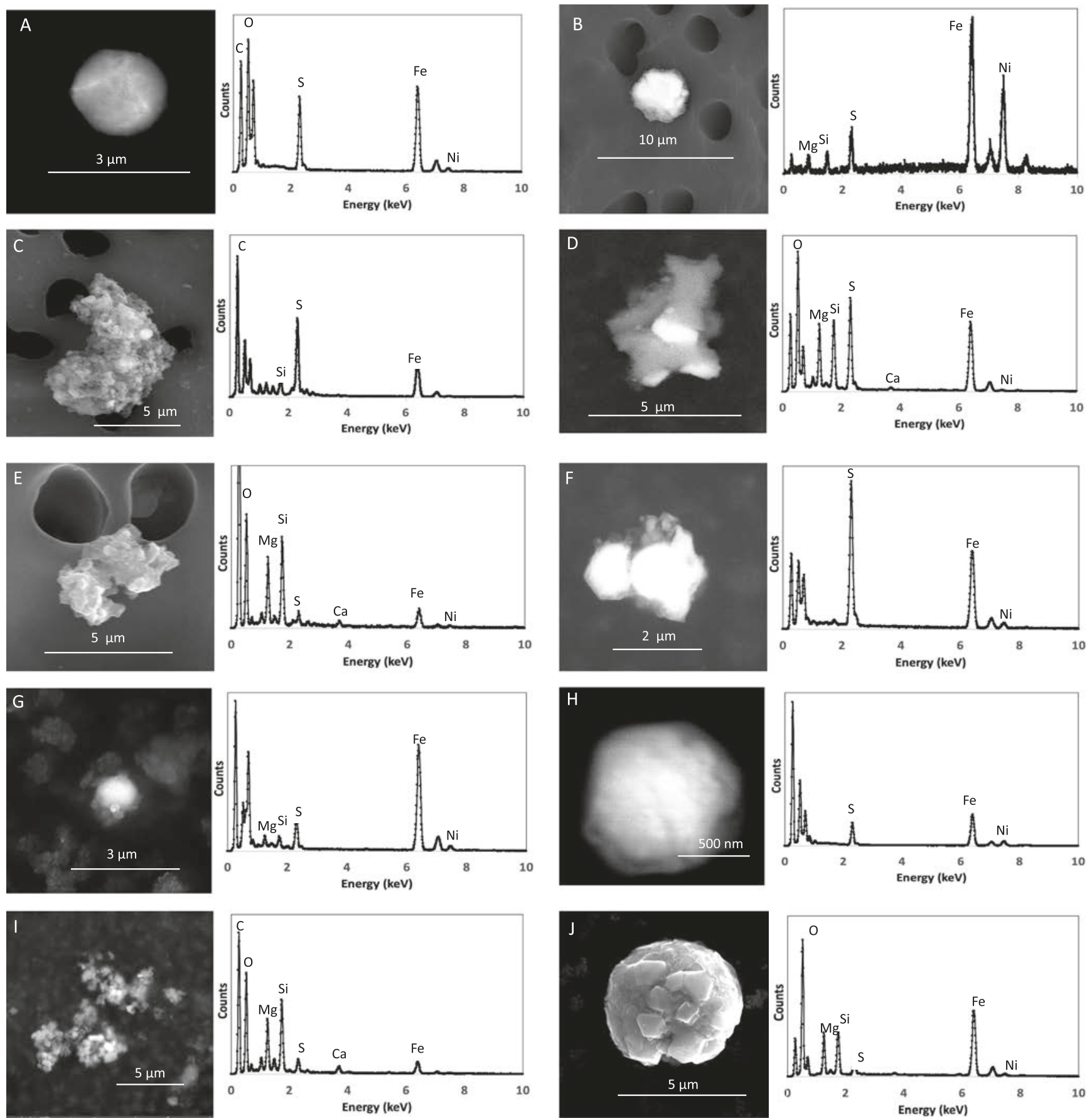

Fig. 8. SEM images and spectra of 10 ET particles found on SPA-10. Shown are secondary electron images of particles A, C, D, E, G, H, and J and backscatter electron images of particles B, F, and I. Two of these (I and J) were analyzed in more detail.

include $\mathrm{Mg}, \mathrm{Si}, \mathrm{Ca}, \mathrm{Fe}$ glasses; C-rich particles; and $\mathrm{FeS}$ grains (Appendix S4 in supporting information). Although these may be ET, more work is needed to determine their origin. Similarly, we found one olivine grain, a mineral which is ubiquitous in ET materials but also not common $(2 \%)$ on the stratospheric collection flags we reviewed from the Cosmic Dust Catalogs (Appendix S5 in supporting information).

One of the more unusual ET candidates is an ultracarbonaceous particle (Fig. 11). This particle is irregularly shaped and quite large, $50 \mu \mathrm{m}$ in diameter (Fig. 11A). It has no GEMS-like grains but may contain 


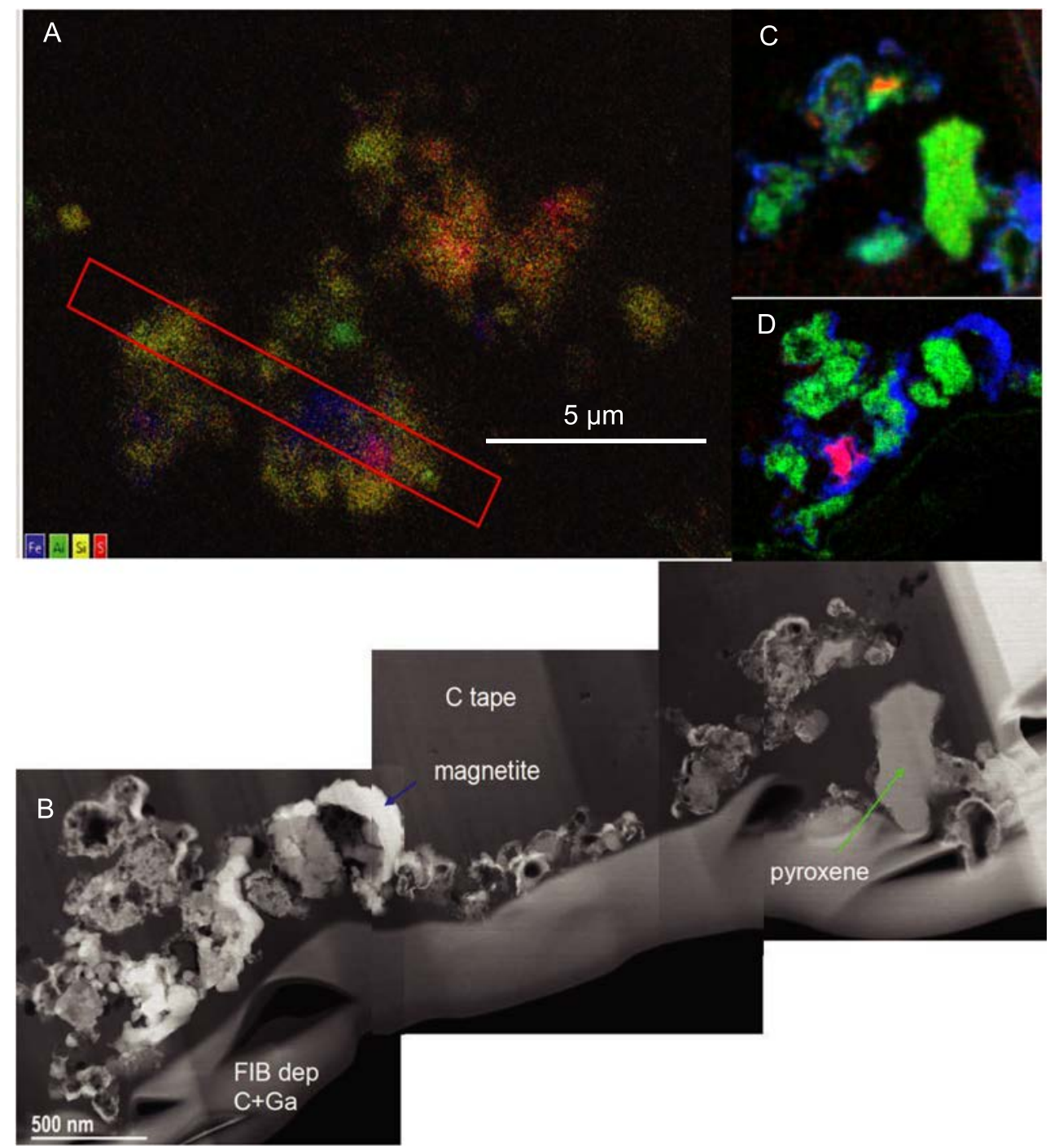

Fig. 9. (A) Area of particle I removed by FIB; (B) overall image of the FIB section, note porous textures and magnetite rims; (C) Fe, $\mathrm{Mg}, \mathrm{Ca}$ element map of top right of $\mathrm{B}$; (D) Fe, S, Si element map of bottom left of (B). Analyses are tabulated in Appendix S3.

enstatite "whiskers," a feature associated with primitive IDPs (Fig. 11B; Bradley et al. 1983). Compositionally, the particle is predominantly $\mathrm{C}$ with $\mathrm{N}, \mathrm{O}, \mathrm{S}$ and minor amounts of $\mathrm{Al}, \mathrm{Si}, \mathrm{Mg}$ (Fig. 11C, bulk composition listed in Appendix S3). The FIB slices show pores that are near or surrounded by $\mathrm{Fe}$ - and Ni-rich material (Fig. 11C). The $\mathrm{Fe}$ is generally associated with $\mathrm{P}, \mathrm{O}$, and $\mathrm{Cr}$, while $\mathrm{Ni}$ is found with $\mathrm{S}, \mathrm{O}$, and in some places $\mathrm{Ca}$-sulfate and several atom\% K. Ni-sulfides and $\mathrm{Fe}$ phosphides (or their hydrated/oxidized counterparts) are not common in IDPs, MM, or meteorites. Flynn et al. (2019) found $\mathrm{P}$ associated with $\mathrm{S}$ in a cluster particle and $\mathrm{Fe}$ sulfides with varying amount of $\mathrm{Ni}$ in GEMS-rich IDPs (Flynn et al. 2016). Only one Ni sulfide has been seen in a micrometeorite (>5000 MMs examined, Taylor, personal communication) and Belyanin et al. (2018) reported Ni-phosphides in the (also enigmatic) HypatiaStone.

NanoSIMS measurements showed a normal $\mathrm{D} / \mathrm{H}$ ratio but slightly elevated ${ }^{15} \mathrm{~N} /{ }^{14} \mathrm{~N}$. The average $\delta{ }^{15} \mathrm{~N} /{ }^{14} \mathrm{~N}$ value of four measurements of three microtomed slices was $47 \pm 7 \%$ (Fig. 11D,E). The N isotopes are homogeneous over the particle slices and although the values are not extremely high, they overlap those seen for bulk insoluble organic matter from some meteorites (e.g., CI chondrites have $\delta^{15} \mathrm{~N} \sim+30 \%$; Alexander et al. 2007). We are unaware of any terrestrial source of carbonaceous material with such an $\mathrm{N}$-isotope signature, and thus think that the enhanced ${ }^{15} \mathrm{~N}$ contents favor an ET origin. 

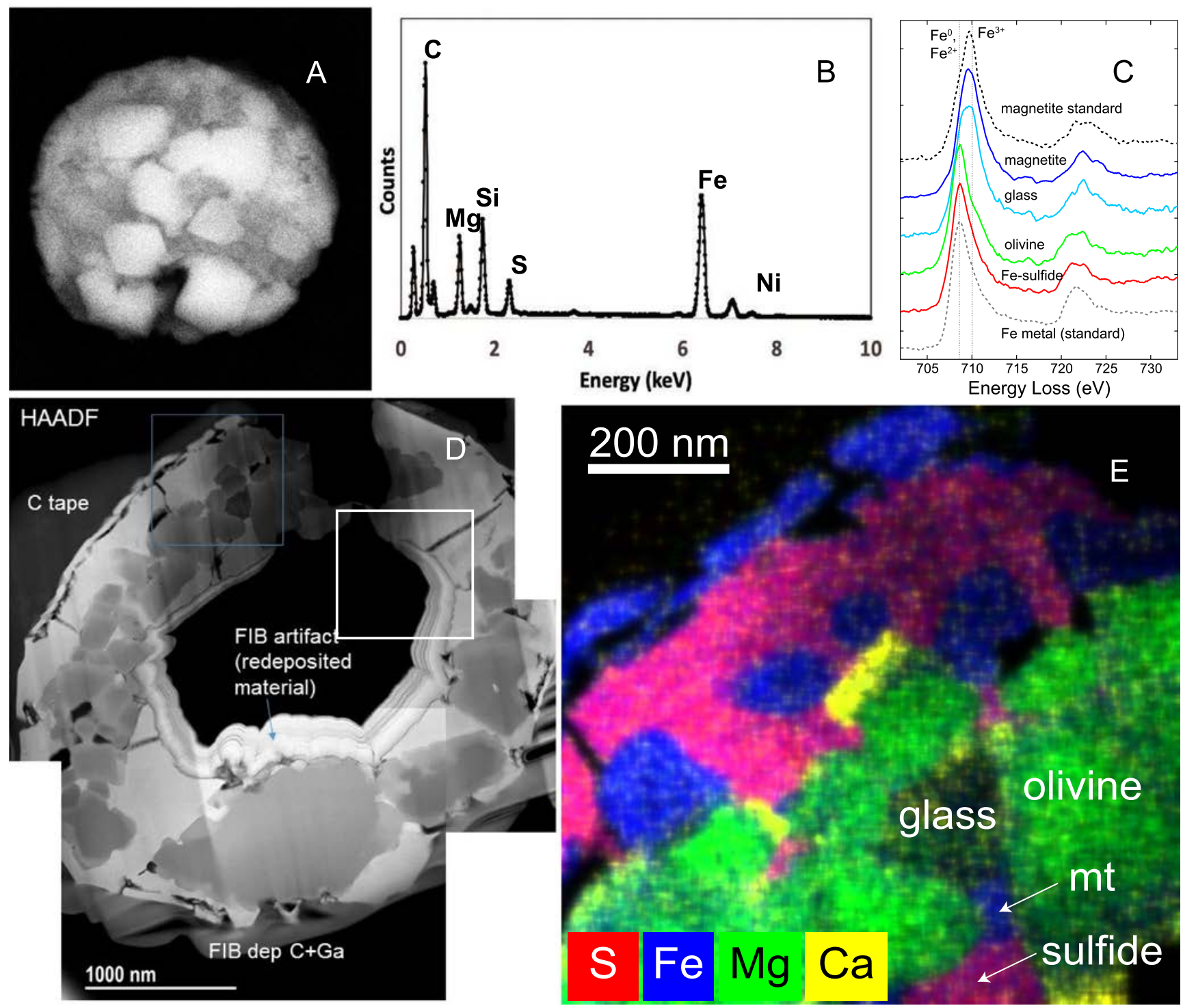

Fig. 10. Data collected on ET particle J. (A) backscatter SEM image; (B) EDS spectrum, Y-axis range 140,000 counts; (C) EELS spectra; (D) HAADF image; and (E) EDS element map of box area shown in the HAADF image.

\section{Helium-3 Measurements}

We detected ${ }^{3} \mathrm{He}$ above blank levels in 178 of the 180 filter subsamples with amounts ranging from $\sim 2$ to $\sim 640 \times 10^{-15}$ cc STP. The average ${ }^{3} \mathrm{He}$ abundance for all $180 \mathrm{~cm}^{2}$ filter subsamples was $69 \times 10^{-15} \mathrm{cc} \mathrm{STP} /$ $\mathrm{cm}^{2} /$ month, with a median value of $19 \times 10^{-15} \mathrm{cc}$ STP $\mathrm{cm}^{-2}$ per month. For stratospheric IDPs, the median ${ }^{3} \mathrm{He}$ concentration is $1 \times 10^{-5}$ cc STP per g, although the span in ${ }^{3} \mathrm{He}$ concentrations is almost a factor of 100 (Pepin et al. 2000).

Using the median values, we estimate the mass of ET material on each subsample to be about
$2 \mathrm{ng} \mathrm{cm}^{-2}$ month $^{-1}$, equivalent to one $5 \mu \mathrm{m}$ spherical particle $\mathrm{cm}^{-2}$ month $^{-1}$ with typical IDP density $\left(1 \mathrm{~g} \mathrm{~cm}^{-3}\right.$; Flynn and Sutton 1991). This broadly agrees with the original estimate of 1-3 IDPs larger than $5 \mu \mathrm{m} \mathrm{cm}^{-2}$ month $^{-1}$ for the South Pole air samples based on measured stratospheric IDP concentrations (Brownlee et al. 1977; Zolensky and Mackinnon 1985). The ${ }^{3} \mathrm{He}$ input flux calculated from these filters, $1 \times 10^{-12}$ cc STP $\mathrm{cm}^{-2} \mathrm{kyr}^{-1}$, agrees with both the stratospheric input values and the average terrestrial deposition rate of IDPs (Farley, personal communication).

Temporal variations in ${ }^{3} \mathrm{He}$ concentrations across the $\sim 2$ years of measurements spanned by the 13 filters 


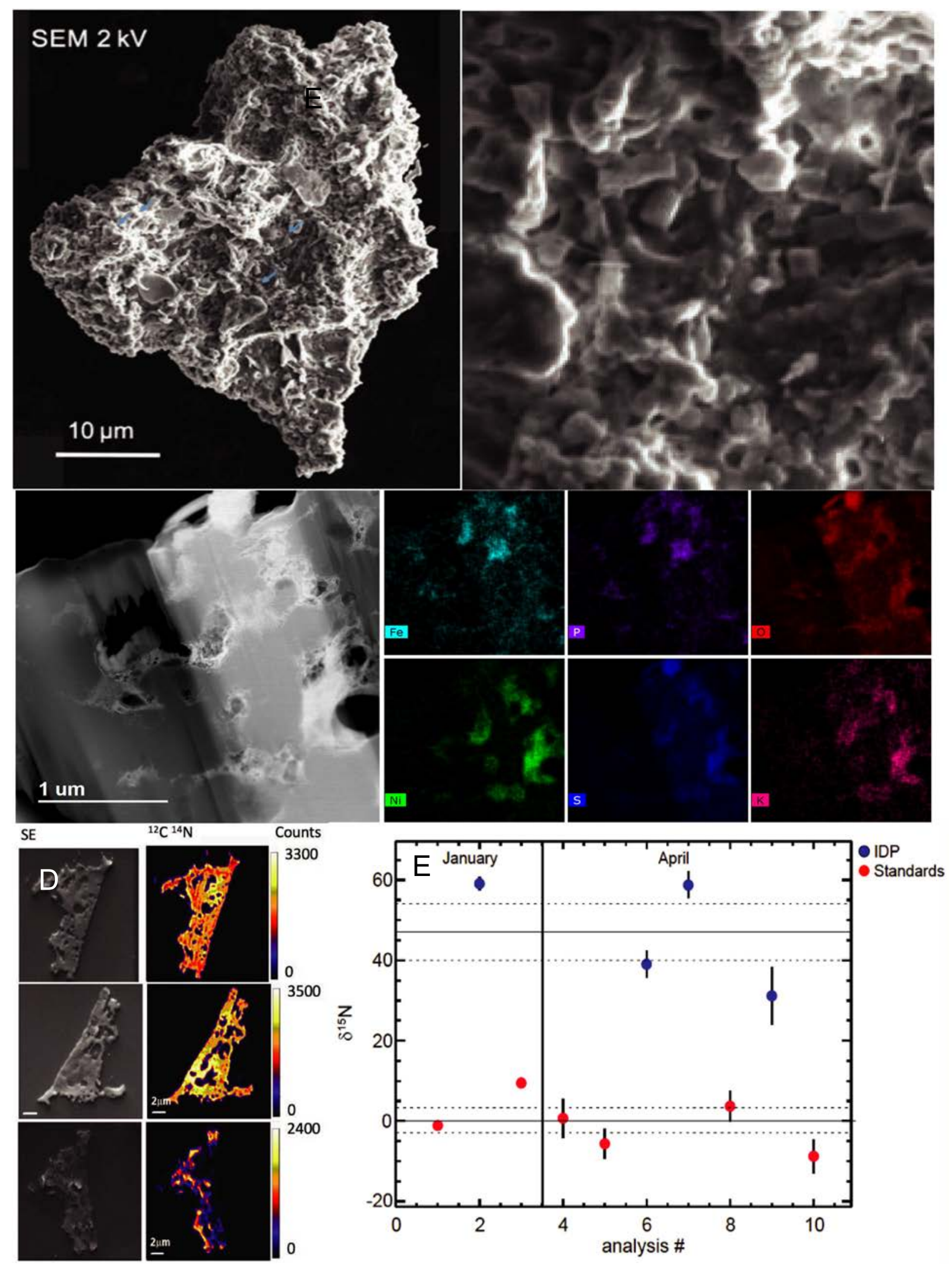


Fig. 11. Carbonaceous ET candidate. (A) SEM image of particle; (B) magnified section, box in A, showing two enstatite whiskers (arrows); (C) STEM of FIB section and element maps; (D) microtome sections and corresponding N isotopic maps; (E) $\mathrm{N}$ isotopic composition of the four microtome sections analyzed, compared to standard measurements made in same analytical sessions. (Color figure can be viewed at wileyonlinelibrary.com.)

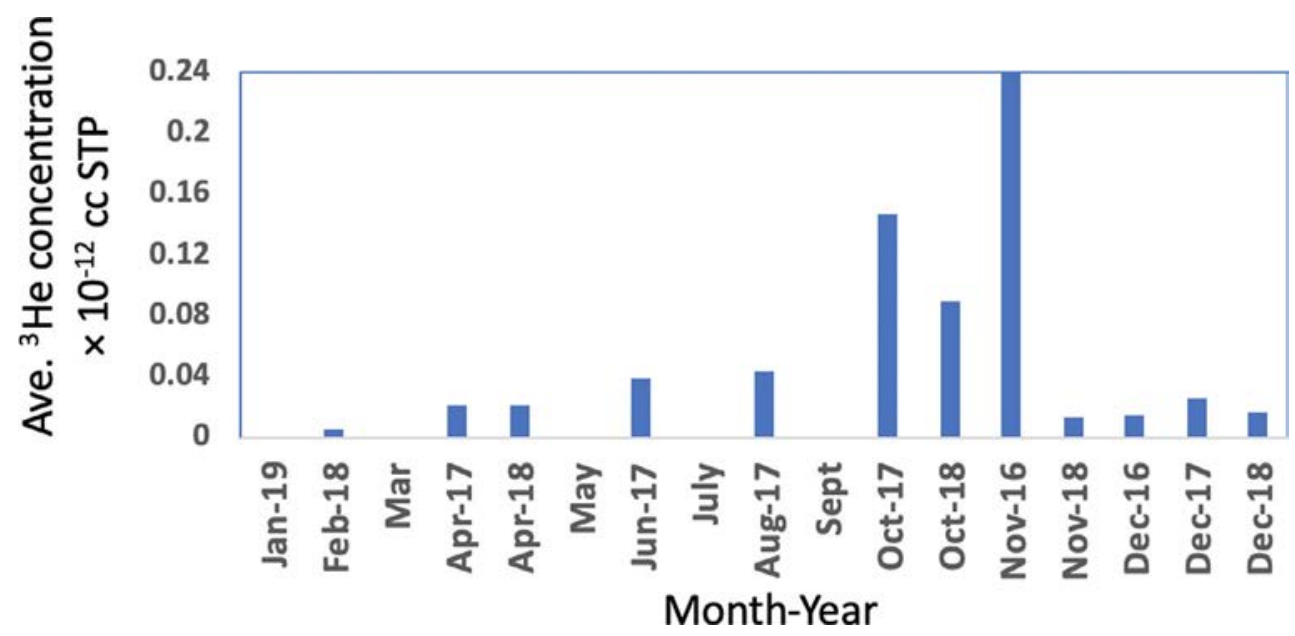

Fig. 12. Average ${ }^{3} \mathrm{He}$ concentrations plotted per month for 2 years of collection. The concentrations were normalized by filter exposure time. The ${ }^{3} \mathrm{He}$ value for SPA-1 (November 2016) lies well above the range plotted at $1.6 \times 10^{-12} \mathrm{cc}$ STP. As no measurements were made of filters collected in March, May, July, or September, these months do not have a year associated with them. (Color figure can be viewed at wileyonlinelibrary.com.)

are shown in Fig. 12. Here, we plot the average ${ }^{3} \mathrm{He}$ concentration of the subsamples, normalized by exposure time, versus the month and year they were collected. We see that the austral spring has elevated ${ }^{3} \mathrm{He}$ deposition relative to other seasons. SPA-1 (November 30, 2016) had the highest concentration $\left(1.6 \times 10^{-12}\right.$ cc STP), followed by SPA-17 (October 16 to November 7, 2018) and SPA-35 (October 22 to November 4, 2019). The value for SPA-1 is not as certain as those for SPA-17 and -35 because the filter was only exposed for $5 \mathrm{~h}$ producing a large multiplying factor when normalized. Also, only three subsamples of SPA-1 were analyzed. Nevertheless, this filter likely has high levels of ET material because we found an $8 \mu \mathrm{m}$ IDP on the single $1 \mathrm{~cm}^{2}$ piece of SPA-1 that was examined by SEM (Fig. 7A) and, furthermore, because the only other filter exposed for a short period of time (SPA-45) had no ${ }^{3} \mathrm{He}$.

To check if the airflow was evenly distributed across the filter, we compared two, $1 \mathrm{~cm}^{2}$ filter subsamples cut from the edges and two, $1 \mathrm{~cm}^{2}$ filter subsamples cut from the center of six filters. We found a fourfold increase in ${ }^{3} \mathrm{He}$ concentration in the center subsamples (Table 2). The average ${ }^{3} \mathrm{He}$ concentration of the two center $\mathrm{cm}^{2}$ filter pieces is $0.097 \pm 0.17 \times 10^{-12}$ cc STP whereas that for the two edge samples of the same filters is $0.023 \pm 0.023 \times 10^{-12} \mathrm{cc} \mathrm{STP}$. Although there is a large variation in the center subsample values, these values are larger than the edge sample in all cases but one (SPA-13).

IDPs are small and should be entrained in the airflow. Nevertheless, to determine whether ET materials adhered to the intake pipes, we wiped down the inside surfaces of each pipe section with a glass filter and analyzed each for ${ }^{3} \mathrm{He}$ (Fig. 13). The data show that above background concentrations of ${ }^{3} \mathrm{He}$ were found on four of the pipe sections (number in bold) ranging from

Table 2. The ${ }^{3} \mathrm{He}$ values $\left(\times 10^{-12}\right.$ cc STP $)$ for two centers and edges, $1 \mathrm{~cm}^{2}$ samples taken from six filters.

\begin{tabular}{lll}
\hline Filter \# & Center & Edge \\
\hline SPA-4 & 0.0154 & 0.0123 \\
& 0.0225 & 0.0128 \\
SPA-8 & 0.0172 & 0.0077 \\
& 0.0227 & 0.0073 \\
SPA-10 & 0.0945 & 0.0114 \\
& 0.08 & 0.0114 \\
SPA-13 & 0.0271 & 0.0468 \\
& 0.0342 & 0.0111 \\
DPA-17 & 0.0814 & 0.042 \\
& 0.6372 & 0.0829 \\
SPA-22 & 0.1284 & 0.0161 \\
& 0.0024 & 0.016 \\
Ave & 0.0969 & 0.0231 \\
Std & 0.175 & 0.023 \\
\hline
\end{tabular}




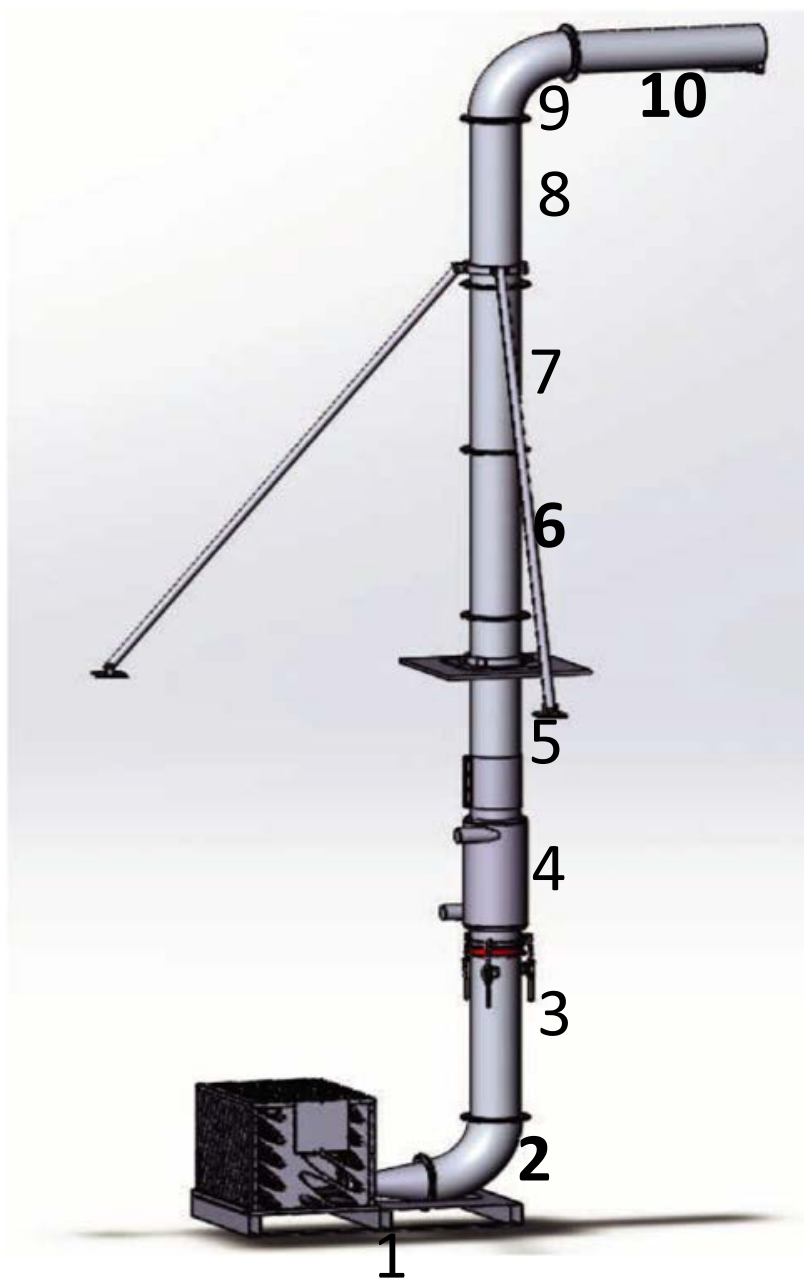

Fig. 13. Schematic of intake pipe sections. Only sections with bold numbers had ${ }^{3} \mathrm{He}$ values higher than background. (Color figure can be viewed at wileyonlinelibrary.com.)
0.015 to $0.075 \times 10^{-12}$ cc STP. One of these pipe sections was below the filter, indicating that small amounts of ET material passed through the filter. Given that each filter used to wipe down a pipe cleaned an area $\sim 6.2 \times 10^{3} \mathrm{~cm}^{2}$ that was exposed for 25 months, the ET concentrations in the wipes were four orders of magnitude smaller than the concentrations in each $1 \mathrm{~cm}^{2}$ filter subsample. Based on these values, we conclude that insignificant amounts of ET materials are adhering to the pipes or flowing through the filters.

\section{DISCUSSION}

The number of ET particles larger than $5 \mu \mathrm{m}$ found on the filter pieces examined is about one-fifth of the number we expected based on the $>5 \mu \mathrm{m}$ IDP stratospheric concentrations and our air-intake rate (one IDP larger than $5 \mu \mathrm{m}$ per $\mathrm{cm}^{2}$ per month of exposure). Although we found smaller and fewer IDPs than we expected, ${ }^{3} \mathrm{He}$ measurements on 180 individual $1 \mathrm{~cm}^{2}$ pieces of filter indicate an average ET mass equivalent to one $5 \mu \mathrm{m}$ IDP per $\mathrm{cm}^{2}$, comparable to the expected value. Given this agreement in expected mass, the smaller sizes and number of ET particles that we were able to locate suggest disaggregation of the IDPs into small pieces that are not easily identified as ET particles on the filters. We do not think that turbulent air-flow systematically disaggregated the IDPs as thin and delicate salt rods survive unbroken (Fig. 5D). Rather, we postulate that exposure to submicron sulfuric acid droplets is the primary cause of IDP disaggregation.

In support of this interpretation, we note that some particles on the filters show evidence of having been dissolved. For example, Fig. 14A,B show holes in

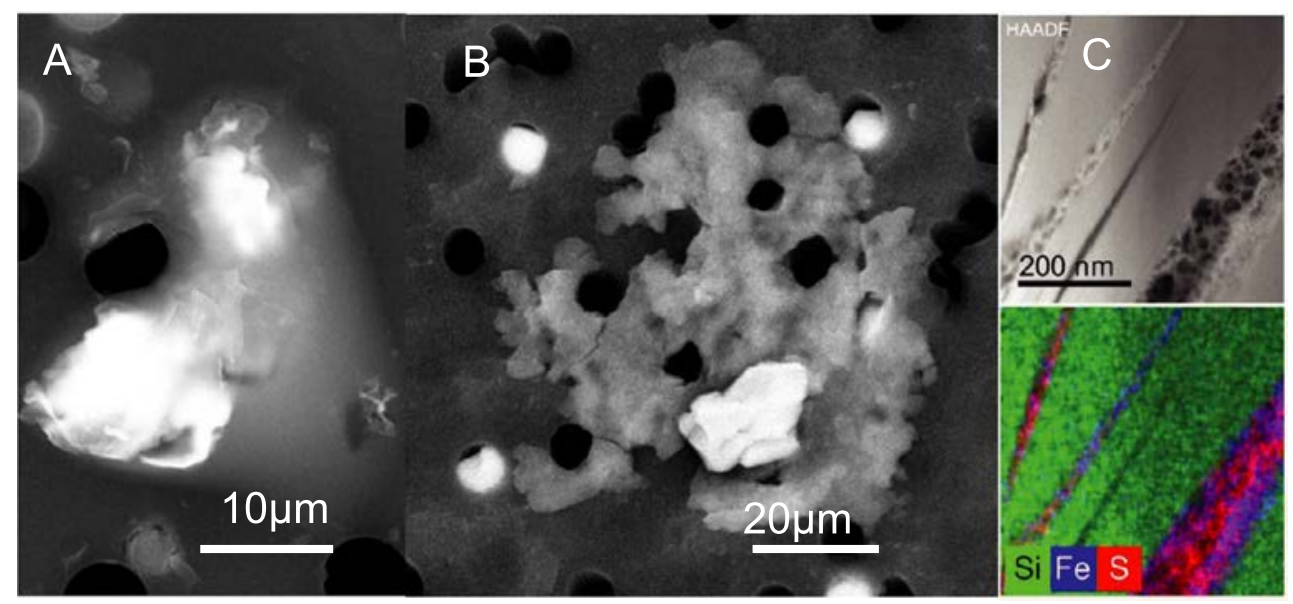

Fig. 14. SEM backscatter electron image of (A) a stainless steel particle in an S-rich droplet and (B) a dissolving Al grain; (C) STEM HAADF and EDS map of vesicular S-rich material in talc from filter SPA-3. 
stainless steel and Al particles at the location of the filter pores. We also observe that the majority of small FeNiS beads come from the C sticky mats, which pull material out of the filter pores. Lastly, we found vesicular S-rich material in the interstices of the weather balloon talc particles (Fig. 14C). The S must come from aerosols interacting with the talc either in the atmosphere or while on the filter, as the talc particles sampled from the balloon staging table contained no S. It is also possible that the IDPs are altered by aerosol droplets in the stratosphere and during transit through the atmosphere to the ground (20-70 days for $10 \mu \mathrm{m}$ particles, depending on their densities).

The South Pole's inaccessibility increases the duration of sulfuric acid exposure relative to other dry IDP collections, for example, those describe by Ishii et al. (2017) and Messenger et al. (2015). During the 8month winter season, the filters cannot be retrieved or analyzed, and return transit of the filters takes several weeks after the station reopens. This lag prolongs the contact time between the sulfuric acid aerosols and the IDPs significantly beyond their 2-week average residency on the filters during collection. Indeed, we found liquid sulfuric acid in the filter pores 2 years after collection.

\section{CONCLUSION}

As the most primitive ET materials known, IDPs are of great scientific interest. Suctioning them from the air at the surface of the Earth would avoid exposing them to silicone oil, solvents, or water and could potentially collect high numbers. A continuous record of IDP arrivals to Earth is key to assessing any seasonal variations in their flux, determining their background composition, and allowing for timed collections to target meteor streams.

We built a collector to obtain 300-900 IDPs per month, with the hope of collecting primitive CP-IDPs, cluster particles, and ultra-carbonaceous MMs. Our sampling strategy used long duration, continuous dry filtering of surface air in place of short duration, highspeed impact collection on flags flown in the stratosphere, and potentially could sample specific meteor streams and measure seasonal variations in IDP flux. We filtered $\sim 10^{7} \mathrm{~m}^{3}$ of clean Antarctic air using $20 \mathrm{~cm}$ diameter, $3 \mu \mathrm{m}$ filter coupled with a suction blower of modest power consumption $(5-6 \mathrm{~kW})$. The high air flow rate through the filter, $\sim 400,000 \mathrm{~m}^{3}$ per month, also delivered myriads of submicron aerosols.

We identified 19 ET particles on the $66 \mathrm{~cm}^{2}$ of filter examined; this area represents $\sim 0.5 \%$ of all the filter surfaces exposed to the air at South Pole. The number of large $(>5 \mu \mathrm{m})$ ET particles is about one-fifth of what we expected based on stratospheric counts. Of the 19 ET particles, four were CP-IDPs, seven were FeNiS beads, two were FeNi grains, and six were chondritic material with FeNiS components. Most were $<10 \mu \mathrm{m}$ in diameter and none were cluster particles. We analyzed the ET and ET-candidate particles by a complementary suite of micro-analytical techniques, SEM, STEM, NanoSIMS, and EELS. One highly C-rich ET candidate particle has a small ${ }^{15} \mathrm{~N}$ isotopic excess suggesting that it is ET. The ${ }^{3} \mathrm{He}$ analyses of $180,1 \mathrm{~cm}^{2}$ filter subsamples show the presence of ET matter on 178 of these. Analyses also suggest that the ET flux varies seasonally. Other bulk measurements, for example, organics, may also yield interesting results. The majority of exposed filter surfaces remain to be examined. Filters are now curated at Johnson Space Center in Houston, and will be available for request from the Astromaterials Research and Exploration Science division.

Although there are many advantages in collecting IDPs from the clean air sector at South Pole, these were not fully realized in our project. The large number of $\mathrm{Al}$ particles from our intake pipe precluded our finding enough ET particles to characterize the composition of the sporadic micrometeorite flux and its variation. Also, we think that dissolution and disaggregation of IDPs by sulfuric acid aerosols is occurring either during transport to the ground or while sitting on the filter or both.

Future collections could eliminate the $\mathrm{Al}$ contamination by using a short, polished intake pipe mounted on the top of a two-story building. The height of the building would obviate a long intake pipe while avoiding snow ingestion. Smaller filter diameters would allow for automated search techniques but would filter less air and collect fewer ET particles. If disaggregation of IDPs is occurring on the filters, the effects of aerosols might be mitigated by dusting the filters with snow during exposure. The snow would protect IDPs from most of the direct aerosol impact (as silicone oil does in the stratosphere) and could be subsequently sublimated. If IDPs are being altered significantly during transport through the atmosphere, exposure to sulfuric acid aerosols may be a characteristic common to all terrestrial dry filter collections, as aerosols are not unique to South Pole.

Acknowledgments-We thank Dr. Jeff Grossman, NASA's Emerging Worlds program manager, for funding this project and for added support provided by Dr. Scott Borg, NSF's Antarctic Program manager. We thank our research associates Adam West (2017), TaLee Shue (2018), and Sheryl Seagraves (2019) who conscientiously monitored the operation of the collector 
and changed out the filters. Many people at South Pole helped to make this project a reality but a special thanks to Leah Street, our NSF science support coordinator and to Dan McCreight, our NSF logistics coordinator. We also thank our students Amanda Pinson and Summer Christenson from Dartmouth College and David Bour, an NRL SEAP student intern. Lastly, we thank Dr. Hope Ishii and an anonymous reviewer who provided comments that improved the paper. The authors have no conflict of interests that could affect the results presented in this paper.

\section{Editorial Handling-Dr. Daniel Glavin}

\section{REFERENCES}

Alesbrook L. S., Wozniakiewicz P. J., Jones A. E., Price M. C., Ishii H. A., Bradley J. P., and Brough N. 2017. Atmospheric collection of extraterrestrial dust at the Halley VI Research Station, Antarctica (abstract \#1805). 48th Lunar and Planetary Science Conference. CD-ROM.

Alexander C. M. O’D., Fogel M., Yabuta H., and Cody G. D. 2007. The origin and evolution of chondrites recorded in the elemental and isotopic compositions of their macromolecular organic matter. Geochimica et Cosmochimica Acta 71:4380-4403.

Belyanin G. A., Kramers J. D., Andreoli M. A. G., Greco F., Gucsik A., Makhubela T. V., Przybylowicz W. J., and Wiedenbeck M. 2018. Petrography of the carbonaceous, diamond-bearing stone "Hypatia" from southwest Egypt: A contribution to the debate on its origin. Geochimica et Cosmochimica Acta 223:462-492.

Bodhaine B. A. and Murphy M. E. 1980. Calibration of an automated condensation nuclei counter at South Pole. Journal of Aerosol Science 11:305-312.

Bodhaine B. A., Deluisi J. J., and Harris J. M. 1986. Aerosol measurements at the South Pole. Tellus 33B:223-235.

Bradley J. P. 1994. Chemically anomalous, pre-accretionally irradiated grains in interplanetary dust from comets. Science 265:925-929.

Bradley J. P., Brownlee D. E., and Veblen D. R. 1983. Pyroxene whiskers and platelets in interplanetary dust: evidence of vapour phase growth. Nature 301:473-477.

Brownlee D. E., Ferry G. V., and Tomandl D. 1976. Stratospheric aluminum oxide. Science 191:1270-1271.

Brownlee D. E., Tomandl D. A., and Olszewski E. 1977. Interplanetary dust: A new source of extraterrestrial material for laboratory studies. Proceedings, 8th Lunar Science Conference. pp. 149-160.

Busemann H., Nguyen A. N., Cody G. D., Hoppe P., Kilcoyne A. L. D., Stroud R. M., Zega T. J., and Nittler L. R. 2009. Ultra-primitive interplanetary dust particles from the comet 26P/Grigg-Skjellerup dust stream collection. Earth and Planetary Science Letters 288:44-57.

Dartois E., Engrand C., Brunetto R., Duprat J., Pino T., Quirico E., Remusat L., Bardin N., Briani G., Mostefaoui S., Morinaud G., Crane B., Szwec N., Delauche L., Jamme F., Sandt C., and Dumas P. 2013. Ultracarbonaceous Antarctic micrometeorites, probing the solar system beyond the nitrogen snow-line. Icarus 224:243-252.
Dobrica E., Engrand C., Duprat J., Gounelle M., Leroux H., Quirico E., and Rouzaud J.-N. 2009. Connection between micrometeorites and Wild 2 particles: From Antarctic snow to cometary ices. Meteoritics \& Planetary Science 44:1643-1661.

Duprat J., Dobrica E., Engrand C., Aleon J., Marrocchi Y., Mostefaoui S., Meibom A., Leroux H., Rouzaud J.-N., Gounelle M., and Robert F. 2010. Extreme deuterium excesses in ultracarbonaceous micrometeorites from central Antarctic snow. Science 328:742-745.

Flynn G. J. and Sutton S. R. 1991. Cosmic dust particle densities-Evidence for two populations of stony micrometeorites. 21st Lunar and Planetary Science Conference. p. 541.

Flynn G. J., Keller L. P., Wirick S., Hu W., Li L., Yan H., Huang X., Nazaretski E., Lauer K., and Chu Y. S. 2016. High-nickel iron-sulfides in anhydrous, GEMS-rich IDPs. 79th Annual Meeting of the Meteoritical Society.

Flynn G. J., Wirick S., and Northrup P. 2019. P speciation in large, cluster interplanetary dust particles (abstract \#1403). 50th Lunar and Planetary Science Conference. CD-ROM.

Hogan A. W., Barnard S., and Bortiniak J. 1979. Physical properties of the aerosol at the South Pole. Geophysical Research Letters 6:845-848.

Ishii H. A., Bradley J. P., Dai Z. R., Chi M., Kearsley A. T., Burchell M. J., Browning N. D., and Molster F. 2008. Comparison of Comet $81 \mathrm{P} /$ Wild 2 dust with interplanetary dust from comets. Science 319:447-450.

Ishii H. A., Wozniakiewicz P. J., Bradley J. P., Farley K. A., and Martinsen M. 2017. Extraterrestrial dust collection at Mauna Loa observatory, Hawai'I (abstract \#1141). 47th Lunar and Planetary Science Conference. CD-ROM.

Ito T. 1985. Study of background aerosols in the Antarctic troposphere. Journal of Atmospheric Chemistry 3:69-91.

Mellor M. 1965. Blowing snow. Cold regions science and engineering, Part III, Section A3c. Hanover, New Hampshire: Cold Regions Research and Engineering Laboratory.

Messenger S. 2000. Identification of molecular-cloud material in interplanetary dust particles. Nature 404:968-971.

Messenger S. 2002. Opportunities for the stratospheric collection of dust from short-period comets. Meteoritics \& Planetary Science 37:1491-1505.

Messenger S., Keller L. P., Stadermann F. J., Walker R. M., and Zinner E. 2003. Samples of stars beyond the solar system: Silicate grains in interplanetary dust. Science 300:105-108.

Messenger S., Nakamura-Messenger K., Keller L. P., and Clemett S. J. 2015. Pristine stratospheric collection of interplanetary dust on an oil-free polyurethane foam substrate. Meteoritics \& Planetary Science 50:1468-1485.

Nittler L. R., Alexander C. M. O'D., Davidson J., Riebe M. E. I., Stroud R. M., and Wang J. 2018. High abundances of presolar grains and ${ }^{15} \mathrm{~N}$-rich organic matter in CO3.0 chondrite Dominion Range 08006. Geochimica et Cosmochimica Acta 226:107-131.

Noguchi T., Ohashi N., Tsujimoto S., Mitsunari T., Bradley J. P., Nakamura T., Toh S., Stephan T., Iwata N., and Imae N. 2015. Cometary dust in Antarctic snow and ice: Past and present chondritic porous micrometeorites preserved on the Earth's surface. Earth and Planetary Science Letters 410:1-11.

Patterson D. B. and Farley K. A. 1998. Extraterrestrial ${ }^{3} \mathrm{He}$ in seafloor sediments: Evidence for correlated $100 \mathrm{kyr}$ 
periodicity in the accretion rate of interplanetary dust, orbital parameters, and Quaternary climate-Orbital inclination, not eccentricity. Geochimica et Cosmochimica Acta 62:3669-3682.

Pepin R. O., Palma R. L., and Schlutter D. J. 2000. Noble gases in interplanetary dust particles, I: The excess helium3 problem and estimates of the relative fluxes of solar wind and solar energetic particles in interplanetary space. Meteoritics \& Planetary Science 35:495-504.

Sheridan P., Andrews E., Schmeisser L., Vasel B., and Ogren J. 2016. Aerosol measurements at South Pole: Climatology and impact of local contamination. Aerosol and Air Quality Research 16:855-872.

Taylor S., Messenger S., and Folco L. 2016a. Cosmic dust: Finding a needle in a haystack. Elements 12:171-176.

Taylor S., Lever J. H., Alexander C. M. O'D., Brownlee D. E., Messenger S., Nittler L. R., Stroud R. M., Wozniakiewicz P., and Clemett S. 2016b. Sampling

\section{SUPPORTING INFORMATION}

Additional supporting information may be found in the online version of this article.

Appendix S1. A condensed version of the dust collector data sheet.

Appendix S2. Image and spectra of (a) W7017A9 and (b) SPA-1, multicomponent, $10 \times 5 \mu \mathrm{m}$ IDPs.

Appendix S3. SEM-EDX analyses of (a) phases in IDP from SPA-10, particle I; (b) phases in SPA-10 ET interplanetary dust particles from Antarctic air. 80th Meteoritical Society meeting, Berlin, Germany.

Thomas K. L., Blanford G. E., Keller L. P., Klock W., and McKay D. S. 1993. Carbon abundance and silicate mineralogy of anhydrous interplanetary dust particles. Geochimica et Cosmochimica Acta 57:1551-1566.

Witkowski R. E. 1988. A search for the cosmic dust increment to aerosol particles at the geographic South Pole. PhD thesis, University of Pittsburgh.

Wozniakiewicz P. J., Bradley J. P., Price M. C., Zolensky M. E., Ishii H. A., Brownlee D. E., Dearborn D., Jones T., Barnett B., Yakuma S., Letendre T., Gonzalez C., Bastien R., and Rodriguez M. 2014. Initial results from the Kwajalein micrometeorite collections (abstract \#1832). Lunar and Planetary Science Conference. CD-ROM.

Zolensky M. E. and Mackinnon I. D. R. 1985. Accurate stratospheric particle size distribution from a flat plate collection surface. Journal of Geophysical Research 90:5801-5808.

particle J; (c) bulk analyses of C-rich candidate particle found on filter SPA-3. S stands for silicate.

Appendix S4. The South Pole air filter has particles of: (A) chondritic glass composition; (B) FeS grains; and (C) carbon-rich grains containing sulfides devoid of $\mathrm{Ni}$. These types of particles may ET, but additional analyses are needed to show that they are extraterrestrial.

Appendix S5. Types of cosmic particles found on flags W7017 and W7029 described in Vol 1 and 2 of the Cosmic Dust Catalog. 


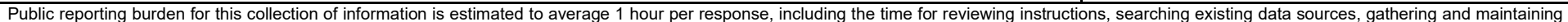

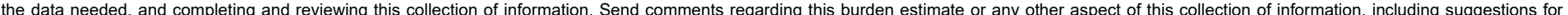

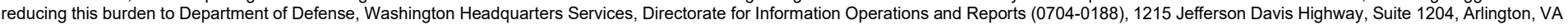

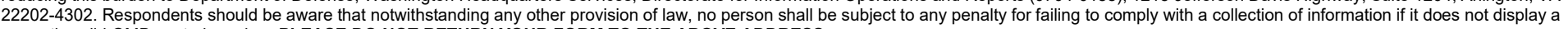
currently valid OMB control number. PLEASE DO NOT RETURN YOUR FORM TO THE ABOVE ADDRESS.
1. REPORT DATE
January 2022

\section{TITLE AND SUBTITLE}

Sampling Interplanetary Dust from Antarctic Air
3. DATES COVERED (From - To)

\section{5a. CONTRACT NUMBER}

5b. GRANT NUMBER

5c. PROGRAM ELEMENT NUMBER

\section{5d. PROJECT NUMBER}

5e. TASK NUMBER

5f. WORK UNIT NUMBER

8. PERFORMING ORGANIZATION REPORT NUMBER

ERDC/CRREL MP-22-1

10. SPONSOR/MONITOR'S ACRONYM(S)

National Aeronautics and Space Administration, Houston, TX

National Science Foundation, Alexandria, VA

11. SPONSOR/MONITOR'S REPORT NUMBER(S)

\section{DISTRIBUTION / AVAILABILITY STATEMENT}

Approved for public release; distribution is unlimited.

\section{SUPPLEMENTARY NOTES}

This article was originally published online in Meteoritics \& Planetary Science on 27 May 2020.

Funding for this project provided by NASA's Emerging Worlds Program and by NSF's Antarctic Program.

\section{ABSTRACT}

We built a collector to filter interplanetary dust particles (IDPs) larger than $5 \mu \mathrm{m}$ from the clean air at the Amundsen Scott South Pole station. Our sampling strategy used long duration, continuous dry filtering of near-surface air in place of short duration, high-speed impact collection on flags flown in the stratosphere. We filtered $\sim 107 \mathrm{~m}^{3}$ of clean Antarctic air through $20 \mathrm{~cm}$ diameter, $3 \mu \mathrm{m}$ filters coupled to a suction blower of modest power consumption $(5-6 \mathrm{~kW})$. Our collector ran continuously for 2 years and yielded 41 filters for analyses. Based on stratospheric concentrations, we predicted that each month's collection would provide 300-900 IDPs for analysis. We identified 19 extraterrestrial (ET) particles on the $66 \mathrm{~cm}^{2}$ of filter examined, which represented $\sim 0.5 \%$ of the exposed filter surfaces. The 11 ET particles larger than $5 \mu \mathrm{m}$ yield about a fifth of the expected flux based on $>5 \mu \mathrm{m}$ stratospheric ET particle flux. Of the $19 \mathrm{ET}$ particles identified, four were chondritic porous IDPs, seven were FeNiS beads, two were FeNi grains, and six were chondritic material with FeNiS components. Most were $<10 \mu \mathrm{m}$ in diameter and none were cluster particles. Additionally, a carbon-rich candidate particle was found to have a small ${ }^{15} \mathrm{~N}$ isotopic enrichment, supporting an ET origin. Many other candidate grains, including chondritic glasses and $\mathrm{C}$-rich particles with $\mathrm{Mg}$ and $\mathrm{Si}$ and $\mathrm{FeS}$ grains, require further analysis to determine if they are ET. The vast majority of exposed filter surfaces remain to be examined.

\section{SUBJECT TERMS}

Interplanetary dust; Antarctica; Amundsen Scott South Pole Station (Antarctica); Air sampling apparatus; Filters and filtration

\section{SECURITY CLASSIFICATION OF:}

\section{a. REPORT}

Unclassified

\section{b. ABSTRACT \\ Unclassified}

c. THIS PAGE

Unclassified
17. LIMITATION OF ABSTRACT

UU

\section{NUMBER} OF PAGES

\section{9a. NAME OF RESPONSIBLE} PERSON

19b. TELEPHONE NUMBER (include area code) 


\section{PERFORMING ORGANIZATION NAME(S) AND ADDRESS(ES)}

U.S. Army ERDC Cold Regions Research and Engineering Laboratory, Hanover, NH 03775

Materials Science and Technology Division, Naval Research Laboratory, Washington, DC 20375

Department of Astronomy, University of Washington, Seattle, WA 91195

Earth and Planets Laboratory, Carnegie Institute for Science, Washington, DC 20015

Caltech, Pasadena, CA 91125

NASA Johnson Space Center, ARES, Houston, TX 77058

School of Physical Sciences, University of Kent, Canterbury, CT2 7NH, UK 